\title{
DE LA LEGITIMIDAD DEMOCRÁTICA DE LA UNIÓN EUROPEA Y DE LA LEGITIMACIÓN DEMOCRÁTICA DE SUS DECISIONES: UNA REFLEXIÓN SOBRE EL PROYECTO DE CONSTITUCIÓN EUROPEA
}

\author{
JASONE ASTOLA MADARIAGA \\ Profesora titular, Universidad del Pais Vasco
}

\author{
SUMARIO \\ I. Introducción. \\ II. Algunas cuestiones previas. \\ III. La singularidad de la Unión Europea. \\ IV. La Constitución europea. \\ V. Los Estados constitucionales en el siglo XXI
}

\section{INTRODUCCIÓN}

Los recientes acontecimientos mundiales vividos desde Europa han sido un claro ejemplo de que los Estados europeos no comparten una misma visión sobre el papel de Europa en la sociedad global en la que nos movemos ${ }^{1}$. Momentos como éste nos hacen ser conscientes de que el proceso de integración europea es una tarea tan difícil ${ }^{2}$ como necesaria, máxime cuando el proceso de globalización que vivimos, aparece más o menos definido ${ }^{3}$ en su dimensión económica, pero no sucede lo mismo en su dimensión jurídico-

1 Precisamente en el inicio de su mandato la presidencia italiana — http://www.ueitalia2003.it/ITA—abre para los ciudadanos comunitarios un foro de discusión, sobre cómo dotar de eficacia, credibilidad y autoridad a la UE en la escena internacional.

2 La búsqueda de un modelo de integración es una constante en la historia de la Unión Europea, en el Prólogo del libro de Daniela PREDA, Per una Constituzione Federale dell Europa. Lavori preparatori del Comitato di Studi presiduto da P.H. Spaak. 1952-1953, CEDAM, Padova 1996, pp. 69-70, Paul Henri Spaak señala la dificultad de los trabajos del primer Comité de Estudio para la Constitución Europea para armonizar las concepciones jurídicopolíticas de los Estados europeos. Esta dificultad se mantiene hasta la actualidad, un resumen de los intentos doctrinales puede encontrarse en el trabajo de Noemí GARCÍA GESTOSO, «Algunas cuestiones sobre la soberanía en el proceso de integración europea», Revista de Derecho Político, n 57/2003, pp. 157-198, especialmente pp. 
nida también hoy, de que la concepción del Estado como fenómeno jurídico presupone la existencia de un territorio en el que la colectividad humana está organizada políticamente ${ }^{13}$. Y para esa organización «la soberanía reside en el pueblo, se expresa directamente a través del poder constituyente y se objetiva jurídicamente en la Constitución (...) La soberanía no reside, pues en ningún órgano del Estado» ${ }^{14}$. «Son los ciudadanos los que constituyen jurídicamente el Estado, los que legitiman su existencia a través de su manifestación de voluntad $\diamond^{15}$. Y a esto suele añadirse que lo que caracteriza a ese Estado así constituido es que no está sometido a ningún poder ni autoridad exterior, el otro aspecto de la soberanía, la soberanía estatal.

La soberanía tiene, por tanto, dos manifestaciones: una interna, es decir la capacidad de cada pueblo de organizarse políticamente sin injerencias exteriores ${ }^{16}$; y otra externa, es decir, la posibilidad de un Estado organizado de iniciar y mantener relaciones diplomáticas y de todo orden con otros Estados y sujetos internacionales, así como la de participar en procesos de creación y aplicación de normas internacionales ${ }^{17}$. Pero tal concepción, como cualquier otra de una disciplina tan permeable a la realidad como

196-198, donde resume los intentos de definición de la Unión, mayor profundización en el libro de la misma autora, Soberania y nacionalidad (Algunas cuestiones críticas desde la teoría de la constitución), Atelier, Barcelona 2004, especialmente pp. 355-366.

3 Para ver los elementos de controversia en esta definición ver R. BOYER, «Les mots et les realités» en Mondialisation au delà des mythes, Le Decouverte, París, 1997, pp. 13-56; P. HIRST y G. THOMPSON, Globalisation in question: the international economy and the posibilities of gobernance, Cambridge, 1996, p. 22; o P. HIRST, «The global economy myths and realities», en International affairs, $1997 \mathrm{n}^{\circ} 73$, pp. 409-425.

4 Las posiciones que mantiene la doctrina van desde los que entienden que la globalización ha transformado al Estado (M. SHAW, «The state of globalisation: towards a theory of state transformation» en Review of international political economy, nos. 3-4, 1997, pp. 497-513) hasta los que entienden que es el Estado el que tiene un papel preponderante en el proceso de globalización (L. WEISS, «Globalisation and the mythe of powerless state» en New left review, no 225, 1997, pp. 3-27).

5 La globalización plantea una demanda de democracia, fruto de la ilegitimidad radical de sus efectos en el plano político, en este sentido, L. FERRAJOLI, «Per una sfera pubblica del mondo» en Teoría política $\mathrm{n}^{\circ}$ 3, 2001, pp. 3-21; o J. HABERMAS, La costellazione postnazionale. Mercato globale, nazioni e democrażia. Feltrinelli, Milán, 1999, pp. 22-28.

6 Ver Gonzalo MAESTRO BUELGA, «Globalización, inmigración y ciudadanía social», Revista de Derecho de Extranjería, 2003, n 4, pp. 9-42.

7 Como señala M. R. FERRARESE, «Las instituciones jurídicas de la globalización», Jueces para la Democracia. N $\mathrm{N}^{\mathrm{0}}$ 42, 2001, pp. 33-38, la universalización del constitucionalismo viene demandada como respuesta a la ilógica de la globalización.

8 Manuel AHIJADO y Ana AHIJADO, «Globalización, una visión general», Revista de Derecho de la Unión Europea, $\mathrm{n}^{\circ}$ 2, 1 er semestre 2002, pp. 17-34, citan (p. 30) las palabras del Presidente de la Comisión Romano Prodi en el mismo sentido «lograr alguna forma de mejorar la globalización de una forma democráticamente accountable (con transparencia y rendición de cuentas)». Aunque los mismos autores señalan más tarde (p. 33) que la respuesta de la Unión será too little too late, por carencia de voluntad política tanto de la Unión como de sus Estados miembros.

9 Algunas recientes aportaciones doctrinales a este proceso son la de Gustavo ZAGREBELSKY, Diritti e constituzione nell'Unione Europea, Lasterza, Roma 2003; o, desde un punto vista de vista más concreto, la de Roland WINKLER, Integrationsverfassungsrecht das österreichisse Verfassungsrecht und das Recht der Europäischen Union. Koordination, Kooperation, Konflikt, Springer Verlag Gmbh \& Co, Wien 2003, o la de Adam BODNAR, Michal KOWALSKI, Karen RAIBLE, y Franck SCHORKOPF, The emerging constitutional law of the European Union. German and Polish Perspectives, Springer Verlag Gmbh \& Co., Berlín 2003. 
política $^{4}$, desde la que lo único que parece claro es que la globalización carece de democra$\mathrm{cia}^{5}$. Y, como señala Maestro Buelga, ${ }^{6}$ es aquí donde adquiere especial relevancia el constitucionalismo y la cultura constitucional democrática, actuando como parámetro y referencia frente al problema de la legitimidad del gobierno de la globalización ${ }^{7}$. Esta universalización del constitucionalismo debería desplegar sus efectos, fundamentalmente, en la extensión del sistema de protección de derechos de las personas y en la introducción de controles en las sedes de decisión globalizadoras ${ }^{8}$.

Y, si bien en estas páginas no me voy a ocupar de «constitucionalizan» las organizaciones mundiales, sí me voy a referir al proceso de «constitucionalización» de la Unión Europea ${ }^{9}$, fundamentalmente, en aquello que atañe al problema de la legitimidad democrática de las instituciones y decisiones comunitarias. Y esta búsqueda me llevará a la soberanía porque la soberanía permanece invariablemente unida a la legitimidad ${ }^{10}$.

Ahora bien, si existiese un modelo europeo de integración «constitucional» tal modelo podría tener una doble virtualidad, por una parte serviría para el continente pero además podría ser el punto de partida de una organización jurídico-política global ${ }^{11}$.

\section{ALGUNAS CUESTIONES PREVIAS}

Quisiera, por tanto, buscar la lógica jurídica del proceso de integración europea y ver si podemos seguir manteniendo reflexiones como la siguiente: «Mientras la Unión Europea (UE desde ahora) no pueda ser explicada a partir del principio de legitimidad democrática del poder (...) sólo puede ser estudiada "descriptivamente". (...) A esta ausencia de un principio político constitucional rector de la estructura organizativa y de los procedimientos de creación del Derecho en la Unión Europea es a la que se suele hacer referencia, de una manera incorrecta, con la expresión déficit democrático» ${ }^{12}$.

Ya que con éstas o similares palabras explicamos la Unión Europea en nuestras Facultades de Derecho. Porque partimos de la idea, creo que con posibilidades de ser mante-

10 Por todos, Martin KRIELE, Einführung in die Staatslehre: die geschichtlichen Legitimitätsgrundlagen des democratischen Verfassungsstaates, $5^{\text {a }}$ ed., Westdt. Verl., Opladen 1994, p. 19.

11 Ya Guy HERAUD, Le Fédéralisme, Presses d`Europe, París 1968, pp. 17 y ss. decía que el nivel de federación continental o subcontinental, caracterizado por una comunidad de civilización, debe ser reconocido, impulsado y hasta institucionalizado como condición y paso previo a la necesaria y urgente federación mundial. Y en nuestros días M. DELMAS-MARTY, «L`espace judiciaire européen, laboratoire de la mondialisation», What future for Europe, European University Institute, Florencia 2000 y Francisco ALDECOA LUZARRAGA, «Una constitución para la gran Europa democrática», Revista General de Derecho Europeo, n ²/2003, http://www.iustel. $\mathrm{com} /$ revistas entiende que con la Constitución Europa enfrenta sus responsabilidades en la gestión de la globalización.

12 En este caso la cita es de Javier PÉREZ ROYO, Curso de Derecho constitucional, Marcial Pons, 8 a ed., Madrid 2002, p. 1091.

13 T. STEIN, «La Constitución europea: pasado, presente y futuro», Cuadernos Europeos de Deusto, 14/1996, pp. 155-171, considera que la Constitución es el orden fundamental del Estado y sólo puede haberla en un Estado es decir cuando concurren los tres elementos clásicos (pueblo, territorio y poder organizado) que no concurren en la Unión, por lo tanto, en la Unión no cabe ninguna Constitución.

14 PÉREZ ROYO, Ibidem, p. 67.

15 PÉREZ ROYO, Ibidem, p. 83. 
Estados miembros (EEMM, desde ahora) y sus ciudadanos ${ }^{23}$, una vez cumplida su fase de derecho internacional, es decir, una vez ratificados los Tratados (incluso el proyecto de Constitución, presentado por la Convención en el Consejo Europeo de Salónica en junio de 2003 se ciñe al modelo comunitario, es decir, la Constitución se adopta a través de un Tratado internacional ${ }^{24}$ ). Y en eso estriba, precisamente, la singularidad de la Unión Europea que, hasta el momento, escapa de los modelos conceptuales tradicionales de explicación del poder. En la Unión los espacios soberanos de los EEMM y los ámbitos competenciales de la Unión se coordinan entre sí y la decisión de cada Estado de ser parte de la Unión estructura su soberanía de una manera nueva. Por eso, se trataría de que esta relativización de la soberanía no conduzca a su desaparición, como propugna Diez- Picazo ${ }^{25}$, sino a su reinterpretación ${ }^{26}$ como garantía estructural de este nuevo sistema.

\section{LA SINGULARIDAD DE LA UNIÓN EUROPEA}

La Unión europea ha creado un sistema jurídico cuyo origen es de derecho internacional, los tratados comunitarios son voluntariamente aceptados por los Estados soberanos, pero una vez concluida esa fase, la Unión pasa a otro estadio que tiene más similitud con los modelos de derecho interno que con los modelos de derecho internacional ${ }^{27}$. La Unión Europea no es, por tanto, una organización internacional, pero tampoco es un Estado, nos hallamos en un proceso de formación de una nueva estructura político jurídi$\mathrm{ca}^{28}$.

Precisamente por ser un poder emergente, cuando se aborda la naturaleza jurídica de la Unión Europea, las diferentes ramas del Derecho parten en sus análisis de los cánones propios de su especialidad.

16 El art. 2.7 de la Carta de las Naciones Unidas dice lo siguiente: «Ninguna disposición de esta Carta autorizará a las Naciones Unidas a intervenir en los asuntos que son esencialmente de la jurisdicción interna de los Estados, ni obligará a los Miembros a someter dichos asuntos a procedimientos de arreglo conforme a la presente Carta», aunque más tarde prevea salvedades.

17 En este sentido y por todos, Albert RANDELZHOFER, «Staatsgewalt und Souveranität», Handbuch des Staatsrechts, editado por Josef Isensee y Paul Kirchhof, Heidelberg 1987, t. I, \15, p. 700, marg. 24, que señala que no se trata de dos soberanías diferentes, sino de dos aspectos del mismo y único fenómeno que se muestra por una parte en las relaciones internas y por otra en las relaciones exteriores.

18 Como dice Juan José SOLOZABAL, «El problema de la soberanía en el Estado Autonómico», Fundamentos, 1/1998, pp. 461-502, especialmente p. 470: La soberanía no puede ser más que un poder limitado jurídicamente: no hay soberanía que pueda liberarse del derecho, que pueda referirse a un poder del estado capaz de actuar contra el derecho. (...) el poder del Estado es, necesariamente un poder jurídicamente limitado».

19 Aunque esta afirmación puede ser, como dice Antonio DE CABO «¿Crisis del concepto de soberanía?» en Antonio DE CABO y Gerardo PISARELLO (eds.), Constitucionalismo, mundialización y crisis del concepto de soberanía. Algunos efectos en América Latina y Europa, Univ. De Alicante, Alicante 2000, pp. 55-62, especialmente en la p. 61, más «una mera justificación ideológica del mantenimiento de un aparato legitimador que ordenador de la convivencia».

20 La violación de los derechos fundamentales de la minoría kurda y de la población civil iraquí motivó la Resolución 688 (1991) del Consejo de Seguridad de la ONU durante la crisis generada por la invasión de Kuwait por parte de Irak. Y la jurisdicción del Tribunal europeo de derechos humanos es aceptada por todos los Estados europeos que han firmado la Convención europea de derechos humanos. 
es el Derecho constitucional, hay que entenderla con matices, o dicho de otra manera, no tiene un valor absoluto.

En su manifestación interna, y en este estadio histórico de la evolución de este concepto, la soberanía nos aparece como un poder superior, más que supremo, unido al derecho $^{18}$, que resuelve los conflictos entre los órganos del Estado, ya que a través, normalmente, de la Constitución, se establecen los ámbitos de actuación de dichos órganos y por lo tanto se pueden controlar con arreglo a tales criterios; y, simultáneamente, los órganos del Estado legitiman su actuación en la medida en que es conforme a derecho ${ }^{19}$.

En cuanto a su manifestación externa es indudable que el desarrollo que ha tenido el Derecho internacional en el último medio siglo ha sido muy importante, sobre todo en lo que se refiere a la protección de derechos, haciendo posible que cualquier violación de los derechos humanos quede fuera de la jurisdicción interna — de la soberanía estatal-y reclame una actuación internacional ${ }^{20}$. Además de la protección de derechos existen otros temas, como las reglas básicas del comercio internacional que son resueltas en el GATT o la gestión del espacio aéreo y marítimo que se debe hacer de acuerdo a la normativa internacional ${ }^{21}$.

Es decir, la soberanía estatal no es absoluta ni en su ámbito interior ni en su ámbito exterior, ya que en ambos casos está limitada por el derecho (interno o internacional) ${ }^{22}$.

Ahora bien, todos los instrumentos jurídicos internacionales que pueden obligar a los Estados tienen una característica común: cada Estado soberano tiene la libertad de asumir el cumplimiento de una normativa concreta: un tratado, una convención, una resolución, etc. Precisamente en esto estriba la gran diferencia entre la Unión Europea y cualquier organización internacional, ya que la Unión es capaz de crear Derecho obligatorio para sus

21 El art. 2.3 de la Convención de las Naciones Unidas sobre el derecho del Mar de 1982 dice, por ejemplo, que la soberanía sobre el mar territorial se ejerce con arreglo a esta Convención y otras normas de Derecho internacional. Pero como muy bien reflexiona Oscar ALZAGA VILLAAMIL, «Aproximación al mar como elemento del territorio de los Estados», Teoría y Realidad Constitucional, nº 1, 1er semestre 1998, pp. 183-193, especialmente p. 192: «Los protagonistas del escenario político de la humanidad siguen siendo los Estados, pero fenómenos como el de la regulación jurídica de los mares ponen cada vez más claramente de manifiesto las limitaciones que son propias de la Institución estatal para afrontar problemas cuya dimensión y proyección trasciende el ámbito de las fronteras de cada Estado».

22 Por eso aparecen conceptos como offene Staatlichkeit (estatalidad abierta), o integrierte Staatlichkeit (estatalidad integrada), o kooperativer Verfassungsstaat (Estado constitucional cooperativo) para definir al Estado actual, en este sentido es interesante el trabajo de I. PERNICE, «Europäisches und nationales Verfassungsrecht», Veröffentlichungen der Vereinigung der deutschen Staatsrechtslebrer, 2001, (vol. 60), pp. 148-188, especialmente pp. 155156.

$23 \mathrm{El}$ efecto directo del derecho comunitario, que ha sido obra de un poder «constituido», el Tribunal de Justicia, se declaró por primera vez en la sentencia de 5 de febrero de 1963 (Rec. 1963, p. 1) en el asunto 26/62, Van Gend \& Loos.

24 El texto publicado en el DOUE de 18 de julio de 2003, C/169 lleva este título: «Proyecto de Tratado por el que se constituye una Constitución para Europa». Adoptado por consenso por la Convención europea el 13 de junio y el 10 de julio de 2003; presentado al presidente del Consejo Europeo en Roma el 18 de julio de 2003.

25 Su postura está claramente expuesta en Luis María DIEZ-PICAZO, «Europa: las insidias de la soberanía», Claves no 79 , enero-febrero 1998, pp. 8-15.

26 Por todos, Markus KOTZUR, «La soberanía hoy» en Peter HÄBERLE, Markus KOTZUR, De la soberanía al derecho constitucional común: palabras clave para un diálogo europeo-latinoamericano, UNAM, México 2003, p. 21. 
organizada y libre ${ }^{34}$. Porque es un pensamiento extendido el de que la democracia sólo puede llegar a funcionar allí donde exista una previa realidad nacional: sólo quienes comparten un núcleo de tradiciones, creencias y valores estarían en condiciones de organizar su vida colectiva democráticamente ${ }^{35}$.

Aunque también es verdad que un breve repaso histórico nos es suficiente para ver que, en muchos casos, ha sido el Estado, la organización, quien se ha ocupado de crear una sociedad con esas características y no viceversa ${ }^{36}$. Wyduckel entiende que lo mismo pasa con la soberanía, ya que ésta adquiere relevancia en un momento posterior, y no anterior, a la formación del Estado ${ }^{37}$.

Los nuevos conceptos, tan en boga, de patriotismo constitucional ${ }^{38}$ o de lealtad (allegiance $\left.^{39}\right)$, que intentan explicar la adhesión emocional de los ciudadanos a una organización política, porque reúne las exigencias de civilización impuestas por el constitucionalismo, tampoco tienen una organización definida (Estado, Unión, una Región.....) sino que su mensaje estriba en la identificación con un marco político que asegura al ciudadano un status quo. Es decir, se apoya aquello que asegura el mayor nivel de bienestar ${ }^{40}$.

Por otra parte, también se ha intentado crear un marco teórico propio para la UE, como en el caso de Pernice ${ }^{41}$, que habla de un sistema de múltiples niveles de gobierno, o se ha hablado de la soberanía compartida para explicar la Unión ${ }^{42}$, o se ha intentado diluir el propio concepto de Constitución, diciendo que no existe una concepción unánime en la doctrina ${ }^{43}$. O para legitimar las actuaciones de las instituciones comunitarias se ha utilizado una y otra vez la propuesta de acercarlas a las democracias parlamentarias, o semiparlamentarias, es decir, reforzar los poderes del Parlamento europeo y hacer que el Presidente de la Comisión sea elegido directamente por las urnas o indirectamente a través del Parlamento europeo $^{44}$ para, de esta manera, resolver el tan famoso déficit democrático de la UE ${ }^{45}$, aunque hay autores que sostienen que ése no es el problema ya que los ciudadanos euro-

27 Esta idea se repite en la doctrina, por todos, Beatriz PÉREZ DE LAS HERAS, Hacia un derecho común de la Unión Europea, Dykinson, Madrid 2003, p. 14.

28 Para resumir estos intentos nos puede servir el título del trabajo de C. STEPHANOU, «L'Union Européenne et les analogies fédérale et confédérale» en VVAA, Le concept contemporain de Confédération, Strasbourg 1995, pp. 153-157 quien define la confederación como un orden de soberanías coordinadas, frente a la federación que sería un orden de soberanías integradas y la Unión presenta un modelo intermedio.

29 Palabras de Elieen DENZA, «Two Legal Orders: Divergent or Convergent?, International and Comparative Law Quaterly, 1999, pp. 257-284; la falta de legitimidad de la Unión con argumentos semejantes había sido expresada ya por T. SCHILLING, «The Autonomy of the Community Order. An Analysis of Possible Foundations», Harvard Journal of International Law, 1996, especialmente p. 398.

30 Por todos José MARTÍN PÉREZ DE NANCLARES, «La constitución de la UE: reflexiones acerca del debate constitucional pendiente», en Marcelino OREJA AGUIRRE (dir.), El futuro de la Unión Europea: Unión politica y coordinación económica, Dykinson-IEEE San Pablo, Madrid 2002, pp. 37-59 o en su más reciente trabajo, El federalismo supranacional: ¿Un nuevo modelo para la Unión Europea?, Consejo Vasco del Movimiento Europeo, Bilbao 2003, p. 55: «la permanente tensión entre el germen iusinternacionalista de los tratados constitutivos y el surgimiento de unos elementos nuevos explicables tan sólo desde la perspectiva constitucional».

31 En este sentido se expresa J.H.H. WEILER, «Introduction: We Will Do, and Hearken» en WEILER (ed.), The Constitution of Europe: «Do the New Clothes have an Emperor?» and other Essays of European Integration, Cambridge University Press, Cambridge 1999, p. 9: «in these structural terms, the Community resembles much more, is much more, a constitutional legal order than an international legal orden». 
Para los iusinternacionalistas la Unión es algo más que un órgano internacional, y es definida con frases como: los Estados miembros siguen teniendo plena soberanía y lo único que existe es un método de trabajo conjunto - the public international law method of working together ${ }^{29}$-; o el ordenamiento jurídico comunitario tiene elementos nuevos, inexistentes en las demás organizaciones internacionales, de naturaleza claramente constitucio$\mathrm{nal}^{30}$.

Para los constitucionalistas es, en cambio, bastante menos que un Estado (sírvanos las palabras citadas de Pérez Royo) y, en medio, los comunitaristas, nueva disciplina, toman a la Unión como único marco de referencia y analizan sus evoluciones dentro de una lógica propia: la Unión se parece mucho más a un orden constitucional que a un orden internacional $^{31}$. El problema, por tanto, estriba en llegar a una definición común que pueda ser compartida por todas las especialidades.

Desde el punto de vista de los constitucionalistas, mientras no exista un pueblo europeo ni una opinión pública europea que se sienta representada en un Parlamento europeo, cuya mayoría sostenga un Gobierno, la legitimidad de las decisiones comunitarias deriva todavía de los Estados miembros ${ }^{32}$. Ya en la sentencia del 12 de octubre de 1993 (BVerfGE 89, 155), sobre la ratificación del Tratado de Maastricht ${ }^{33}$, el Tribunal Constitucional alemán señaló que, aunque la Unión se dotara de una organización política que cumpliera con los cánones de la democracia, seguiría faltando un presupuesto indispensable para que esta democracia fuera algo más que un aparato jurídico, un pueblo, entendido como una opinión pública informada,

32 Por todos, Javier RUIPEREZ, La «Constitución europea» y la teoría del poder constituyente, Biblioteca Nueva, Madrid 2000 o Laura RONCHETTI, «Sovranazionalità sensa sovranità: La Commissione e il Parlamento dell 'UE», Politica del Diritto, no 2, giugno 2002, pp. 197-255, especialmente p. 235.

33 Benito ALAEZ CORRAL, «Soberanía constitucional e integración europea», Fundamentos 1/1998, http://www.uniovi.es/\%7Econstitucional/fundamentos/primero/index.html señala que tanto el Tribunal Constitucional Federal Alemán principal aunque no exclusivamente en la BVerfGE 89, 155, como el Consejo Constitucional Francés (en adelante CC), en sus tres decisiones sobre el Tratado de Maastricht (Decisiones 92-308 de 9.04.1992; 92-312 de 02.09.1992; y 92-313 de 23.09.1992), pusieron sobre la mesa los tres grandes problemas que se plantean en el Derecho constitucional actual en torno a la influencia del proceso de integración europea sobre la soberanía de los Estados miembros. El primero hace referencia al mantenimiento de la soberanía de la Constitución, el segundo gira en torno a la pervivencia del carácter estatal (soberano) de la unidad política Estado y el tercero se refiere a la salvaguardia del principio democrático.

34 Como dice Luis María DÍEZ-PICAZO, Constitucionalismo en la Unión Europea, Cuadernos Cívitas, Madrid, 2002, p. 70: «Los ciudadanos (...) deben estar al corriente de los principales asuntos públicos, adoptando posiciones valorativas al respecto de los mismos que, una vez agrupadas en grandes corrientes, sirvan de guía y de control para la actuación de los gobernantes».

35 Ibidem, p. 72: «A falta de un acuerdo básico, de naturaleza eminentemente prepolítica, no cabría la democracia».

36 Entre otros E. GELLNER, Nationalism, Weidenfeld y Nicolson Ed., Londres 1997; M. VIROLI, Per amore de la patria. Patriottismo e nazionalismo nella storia, Laterza, Roma/Bari 1995 o Ignacio DE OTTO, Nueva Enciclopedía Jurídica, Seix, Barcelona 1978, «Nación».

37 Ver el interesante trabajo de Dieter WYDUCKEL, «La soberanía en la historia de la dogmática alemana», Fundamentos, 1/1998, pp. 203-293, especialmente p. 290, donde afirma que «la soberanía no es, por consiguiente, la condición de la estatalidad, sino el resultado acabado de la formación de una identidad estatal o supraestatal».

38 Ver Jürgen HABERMAS, «Cittadinanza politica e identità nazionale» en su libro Morale, diritto e politica, Einaudi, Turín 1992, pp. 105 y ss.

39 Fue Alan S. MILWARD, «Allegiance. The Past and the Future», Journal of European Integration History, Vol $1, n^{\circ} 1,1995$, quien introduce este concepto en la Unión Europea; en la p. 14 nos explica: «By allegiance is meant the analysis of all those elements which induce citizens to give their loyalty to institutions of governance, whether 
Las causas hay que buscarlas en aquella fórmula funcionalista que puso en marcha el proceso de integración europea. Se eligió el funcionalismo sectorial, precisamente, porque representaba huir de todo modelo federal que implicase la pérdida de soberanía nacional.

Lo que contaba, desde esta óptica, era llegar a un resultado normativo igual en el sector objeto de la integración y no tanto el modo en el que tal resultado normativo se hubiese producido.

Ha habido, por tanto, muchos intentos de explicar la Unión en su actual fase, que no es más que una fase de transición, aunque creo acertado decir que la Unión tiene un modelo propio que va afirmándose cada vez más a lo largo de sus años de andadura, modelo que es explicado desde diferentes perspectivas, pero para el que, hasta el momento, carecemos de una teoría constitucional (de la integración como la define Rubio Llorente ${ }^{51}$ ).

\section{LA CONSTITUCIÓN EUROPEA}

national, international and supranational» y en su pensamiento hay una relación directa y estrecha entre la lealtad y el Estado del bienestar. Encuentra que los mayores niveles de lealtad al Estado en Europa se dan entre 1945 y 1960 , frente a su ausencia en el siglo XIX.

40 Esta defensa del status quo se hace teoría en el trabajo de Ignacio SANCHEZ CUENCA, «The political basis of support for European Integration», European Union Politics, vol. 1, n 2, 2000, p. 151 y ss. donde al hacer una comparación entre los diferentes apoyos que recibe el proceso de integración de las poblaciones de Dinamarca y España concluye diciendo que cuanto más acabado sea el estado del bienestar y más eficaz la democracia (entre otros factores) en un Estado mayor reticencia habrá a la integración.

41 I. PERNICE, «Multilevel constitutionalism and the Treaty of Amsterdam: European constitutionmaking revisited?», Common Market Law Review, n 4, 1999, pp. 703-750, especialmente p. 729: «The development of the European Union is an open and dynamic constitutional process of (re)allocation and (re)definition of powers in a multilevel system of political governance», posteriormente ha desarrollado la misma idea en «Multilevel constitutionalism in the European Union», European Law Review, 2002, pp. 511-529. En el mismo sentido se expresan G. MARKS, F. W. SCHARPF, Ph. C. SCHMITTER y W. STREECK, Governance in European Union, Sage, Londres 1996.

42 En este sentido, por todos, Antonio La PERGOLA, «¿Para qué una Constitución en la Unión europea?» en M. OREJA AGUIRRE (dir.), La Constitución europea, Universidad Complutense, Madrid 1994, pp. 43-51, especialmente pp. 47-48, donde señala que esta Constitución debería «conjugar el principio de soberanía popular con el principio de soberanía de los Estados miembros». Es decir, volvemos con otro contenido a estadios anteriores en la evolución del concepto de soberanía, es decir, a aquellos momentos en los que la soberanía no residía ni en la Corona ni en la Nación, sino que residía conjuntamente en ambas «Las Cortes con el Rey son la fuente de todas las cosas legítimas», decía el Dictamen de la Comisión de Constitución de 1845 en España.

43 En este sentido, B.M. ZUPANCIC, «From combat to contract or was does the Constitution constitute?», European Review of Public Law, 1999, pp. 11-56, que resalta las diferentes visiones que existen tras una Constitución, desde la visión contractualista hasta la normativista de nuestros días; o J. C. PIRIS, «L'Union européenne a-t-elle une constitution? Lui en faut-il-une?», Revue Trimestrielle de Droit Européen, 1999, pp. 599-635, especialmente en la p. 600, donde da cuenta de la pluralidad semántica del término constitución: desde el ámbito material (según se ocupe de él el derecho internacional o el nacional) o desde el ámbito territorial (estemos en un Estado centralizado o federal) ....

44 En este sentido y por todos Eduardo VIRGALA FORURIA, «El Poder ejecutivo en la UE: Consejo y Comisión», Revista de Estudios Políticos, n 119, enero-marzo 2003, pp. 311-350 y Philipp DANN, «Looking through the federal lens: The semi-parlamentary Democracy of the EU», The Jean Monnet Working Papers n5/2002, http:/ / www.jeanmonnetprogram.org/papers/02/020501.rtf 
peos están tan lejos de las instituciones, las conocen tan poco, que no tienen elementos para juzgarlas asíi ${ }^{46}$.

La distancia entre las instituciones comunitarias y los pueblos de los Estados que forman parte de la Unión ha sido consustancial al propio proceso de integración. La primera razón, y no carente de importancia, pudiera ser que si el proceso de integración hubiera sido democrático lo más probable es que no hubiera comenzado. Las recientes experiencias de referéndum, cincuenta años más tarde, nos sirven de punto de referencia para comprobar que la opinión pública de los Estados está dividida al $50 \%$ a favor y en contra del proceso de integración ${ }^{47}$. Es decir, aunque hagamos abstracción de cómo ha surgido la Unión y creamos que en su proceso de formación no se diferencia de otras estructuras, es decir, que se crea primero la organización y después se trabaja desde ella para conseguir la adhesión de los ciudadanos a la misma, lo que parece claro es que esto no se ha hecho ${ }^{48}$, al menos, de manera suficiente, en la Unión europea ${ }^{49}$.

En los primeros años de andadura comunitaria el objetivo era convencer a las elites europeas de la necesidad y las ventajas del nuevo orden ${ }^{50}$ y los tímidos intentos de la Comisión de acercarse a los ciudadanos a través de políticas sociales, que comenzaron en la década de los sesenta, chocaron con la oposición de los gobiernos de los EEMM.

45 La Presidencia griega de la UE organizó un foro de debate en línea, del 1 al 15 de junio de 2003, con el que se pretendía conocer la opinión de los ciudadanos europeos respecto a que sea el Parlamento Europeo quien elija al Presidente de la Comisión Europea. El Foro debatió sobre si dicha propuesta resultaba o no suficiente para reforzar la legitimidad democrática de las Instituciones europeas: http://www.eu2003.gr/en/forum/

46 Así se ha expresado Joaquim SCHILD, «National v. European Identities», Journal of Common Market Studies, Vol. 29, $\mathrm{n}^{\circ}$ 2, 2001 y la misma idea es barajada en Jean BLONDEL y otros, People and Parliament in the European Union. Participation, Democracy and Legitimacy, Clarendon Press, Oxford 1998.

47 En la página de Internet http://europa.eu.int/futurum/documents/press/pr170603_es.pdf se da cuenta de los resultados del eurobarómetro en junio de 2003 y nos encontramos con el siguiente dato: « Alrededor del 54\% (de la ciudadanía) piensa que la pertenencia de su país a la UE es positiva. Al mismo tiempo un 50\% piensa que su país se ha beneficiado de la integración» (p. 2). Más datos en la siguiente página de Internet: http:// europa.eu.int/comm/public.opinion

48 Gurutz JÁUREGUI, «La Unión Europea ante el proceso de globalización: respuestas políticas, culturales y sociales» en El euro como expresión de modelo federal y social europeo, Consejo Vasco del Movimiento Europeo, Bilbao 2002, pp. 63-78, especialmente p. 76, antes de decir que la sedimentación de un sentimiento europeo va a resultar totalmente imprescindible para el futuro señala que «Con respecto al sentimiento común, la UE aparece hasta el momento como una estructura fría, racional, cartesiana, que no está por ahora en condiciones de apelar a un consenso de sentimientos».

49 Según el documento que refleja la última encuesta del Eurobarómetro, realizada tras el Consejo Europeo de Salónica de junio de 2003, que puede encontrarse en la dirección de Internet: http:/ / europa.eu.int/ comm/public_opinion/flash/fl142_convention.pdf el 55\% de los ciudadanos de la UE nunca ha oído hablar de la Convención Europea y el 52\% ignora el tipo de texto elaborado por la Convención. Por otro lado, el proyecto de Tratado Constitucional presentado por la Convención cuenta con la aprobación de tan sólo el 9\% de los europeos mientras que el $43 \%$ por ciento desea la modificación parcial del mismo, el $8 \%$ que se cambie radicalmente, y el $11 \%$ prefiere mantener en vigor los tratados existentes. Los datos muestran asimismo que una clara mayoría de ciudadanos europeos (el 68\%) apoya la existencia de una auténtica Constitución europea, porcentaje que supera el $80 \%$ en España, Italia, y Hungría.

50 Michel NEWMAN, «Allegiance, Legitimation, Democracy and European Union», EUI Working Paper, HEC $n^{\circ} 5 / 2001$, p. 3 califica estos primeros tiempos como los de «permissive consensus» y señala que entonces era más importante la asunción del orden comunitario por los sistemas judiciales de los EEMM que por sus poblaciones. Este texto puede consultarse en la dirección http://www.iue.it/PUB/hec01-05.pdf 
Y para el estudio de ese modelo partiré de un ejemplo: el art. 1 del proyecto de Constitución europea. En la primera columna aparece la versión que se intentó en los primeros borradores y en la segunda la última versión presentada por la Conferencia de los representantes de los gobiernos de los Estado miembros en Bruselas el 29 de octubre de $2004^{52}$ :

51 Francisco RUBIO LLORENTE, «El constitucionalismo de los Estados integrados de Europa», Revista española de Derecho Constitucional, $\mathrm{n}^{\circ} 48,1996$, pp. 9-33, especialmente p. 31: «(...) esa teoría constitucional de la integración de la que todavía carecemos y cuya creación es una exigencia práctica (...) «la legitimación por el éxito», en el supuesto de que tal cosa exista, es difícilmente compatible con el Estado de Derecho, o la Rechtsgemeinschaft»; En el mismo sentido, Javier TAJADURA TEJADA, «La crisis de la Constitución en el proceso de integración europea», Revista de Derecho Político, $\mathrm{n}^{\circ}$ 53, 2002, pp. 241-269, especialmente p.268: «(...) los problemas (...) tienen su raíz en la falta de fundamentación constitucional del proceso de construcción europea».

52 Versión que puede encontrarse en la página de la CIG o en http://ue.eu.int/cms3_fo/showPage. asp?lang $=$ es\&id $=748 \&$ mode $=\mathrm{g} \&$ name $=\mathrm{La}$ versión anterior de 13 de octubre podía encontrarse en http://ue. eu.int $/$ howPage.asp?lang=es\&id $=251 \&$ mode $=$ g\&name 


\begin{tabular}{|c|c|}
\hline Artículo 1: Creación de la Unión & Artículo I-1: Creación de la Unión \\
\hline $\begin{array}{l}\text { 1. La presente Constitución, que nace de la } \\
\text { voluntad de los pueblos y de los Estados de } \\
\text { Europa de construir un futuro común, crea una } \\
\text { Unión [lamada...], en cuyo seno se coordinarán } \\
\text { las políticas de los Estados miembros y que } \\
\text { gestionará, según un modelo federal, algunas } \\
\text { competencias comunes. } \\
\text { 2. La Unión respeta la identidad nacional de sus } \\
\text { Estados miembros. } \\
\text { 3. La Unión está abierta a todos los Estados } \\
\text { europeos cuyos pueblos compartan los mismos } \\
\text { valores, los respeten y se comprometan a pro- } \\
\text { moverlos en común. }\end{array}$ & $\begin{array}{l}\text { 1. La presente Constitución, que nace de la } \\
\text { voluntad de los ciudadanos y de los Estados de } \\
\text { Europa de construir un futuro común, crea la } \\
\text { Unión Europea, a la que los Estados miembros } \\
\text { atribuyen competencias para alcanzar sus obje- } \\
\text { tivos comunes. La Unión coordinará las políti- } \\
\text { cas de los Estados miembros encaminadas a } \\
\text { lograr dichos objetivos y ejercerá, de modo } \\
\text { comunitario, las competencias que éstos le atri- } \\
\text { buyan }{ }^{53} \text {. } \\
\text { 2. La Unión está abierta a todos los Estados } \\
\text { europeos que respeten sus valores y se compro- } \\
\text { metan a promoverlos en común. }\end{array}$ \\
\hline
\end{tabular}

En la primera versión se intentan introducir en la Unión palabras clave en la organización de un Estado: pueblos, gestión según un modelo federal....que no prosperaron, como viene sucediendo cada vez que se ha hecho un intento similar ${ }^{54}$. Y esta fórmula no prospera por razones de diversa índole, entre las que me referiré a los problemas que puede plantear la inclusión de los términos pueblos de Europa y modelo federal.

Si partimos de la idea de que el «poder constituyente» no lo tienen únicamente los Estados, sino los pueblos de Europa se podría entender que estos pueblos no tienen por qué coincidir exactamente con los pueblos de cada Estado-nación ${ }^{55}$. Esto abriría una vía para dar protagonismo en la construcción europea a lo regional y a lo local. Por otra parte, cabría también la posibilidad de que estos pueblos de Europa, así entendidos, quisiesen aprovechar el nuevo marco político-jurídico que ofrece la Unión, para superar fronteras estatales y buscar nuevas maneras de organización. Y esta posibilidad, parece completamente ajena a los deseos de la Convención que redactó el Tratado constitucional, especialmente cuando en el art. I-5.1 se establece que la Unión «Respetará las funciones esenciales

53 En la versión que la Convención presentó ante el Consejo Europeo de Salónica se utilizaba la palabra transfieran en lugar de atribuyan. Este texto puede encontrarse en http://europa.eu.int/eur-lex/es/treaties/dat/ C2003169es.000802.htm y fue publicado en el Diario Oficial n ${ }^{\circ} \mathrm{C} 169$ de 18 de julio de 2003.

54 Un estudio más pormenorizado de esta primera versión puede verse en Paz ANDRÉS SÁENZ DE SANTA MARÍA, «Hacia una Constitución Europea: comentarios sobre los trabajos de la Convención», Revista General de Derecho Europeo, $\mathrm{n}^{\circ}$ 1/2003, http://www.iustel.com/revistas/detalle_revista.asp?id_revistas=13

55 Una visión sugerente de esta posibilidad puede verse en Bartolomé CLAVERO, «¿Qué historia para qué Constitución de qué Europa?», Conferencia en las jornadas sobre Una Constitución para los ciudadanos de Europa (Facultad de Derecho de Sevilla, 23-24 de octubre, 2003) organizadas por Esperanza Gómez Corona, Pablo Gutiérrez Vega y Rosario Leñero Bohórquez, publicado en Revista de Estudios Políticos, n 123, 2004, pp. 101-127. 
Es por lo tanto la Constitución la que crea un reparto de competencias entre ambos niveles de gobierno y es un órgano federal, sea un Tribunal Constitucional o un Tribunal Supremo, el que se encarga de controlar ese reparto.

La legitimidad democrática del Estado federal descansa en un único pueblo soberano en la Federación y en cada pueblo de cada Estado federado en el segundo ámbito de poder. Este sería el espíritu que subyace en la primera versión del art. 1 del proyecto de Constitución, la doble legitimidad Estados/pueblos ${ }^{57}$ :

La presente Constitución, que nace de la voluntad de los pueblos y de los Estados de Europa de construir un futuro común, crea una Unión [llamada...], en cuyo seno se coordinarán las políticas de los Estados miembros y que gestionará, según un modelo federal, algunas competencias comunes.

¿Y por qué no una federación en Europa? Porque sería acertado decir que la Unión cumple con todas las características del modelo federal que he expuesto ${ }^{58}$, salvo una y ésa es la que hace que todo el esquema se venga abajo. Lo que separa a la Unión del Estado federal es el momento constituyente de tal Estado. La inexistencia de un pueblo europeo que se dote de Constitución ha sido el argumento más utilizado en la doctrina ${ }^{59}$, y a mi modo de ver ese argumento sirve para constatar una realidad mucho más básica, aunque menos expresada: los ciudadanos europeos no queremos construir un gran Estado en Europa, queremos la integración entre Estados independientes ${ }^{60}$, aunque parezca una paradoja, y por eso no acaba de producirse ningún «momento constituyente», para que podamos explicar la Unión desde los parámetros tradicionales del Estado constitucional federal ${ }^{61}$.

\section{LA PALABRA CONSTITUCIÓN}

En la andadura comunitaria, las palabras, la discusión sobre terminología ha estado

56 Soy consciente de la simplificación de esta definición, el modelo federal es analizado desde muchas ópticas, sirva de ejemplo el trabajo de Antonio LA PERGOLA, Los nuevos senderos del federalismo, Centro de estudios constitucionales, Madrid 1994. Aunque para respaldar esta simplificación es interesante el trabajo Manuel BALLBÉ y Roser MARTÍNEZ, Soberanía dual y constitución integradora. La reciente doctrina federal de la Corte Suprema norteamericana, Ariel Derecho, Madrid 2003, de él tomaré una frase que recuerda la juez Sandra O’Connor del TS de los Estados Unidos: «...la Constitución deja a los Estados una soberanía residual e inviolable» (p. 59), en palabras textuales: The Constitution instead «leaves to the several States a residuary and inviolable sovereignty,» The Federalist No. 39, p. 246 (C. Rossiter ed. 1961), reserved explicitly to the States by the Tenth Amendment dice en la sentencia del caso New York v. United States 505 US 144 (1992), cuyo texto puede verse en la dirección de Internet http://caselaw. lp.findlaw.com/scripts/getcase.pl?court=US\&vol=505\&invol=144; Este cambio de rumbo en la jurisprudencia del TS norteamericano ha sido estudiado en nuestra doctrina por Fernando REY MARTÍNEZ, «United States $v$. Lopez, y el «nuevo federalismo» norteamericano», Revista Española de Derecho Constitucional, nº 51, 1997, especialmente p. 280 donde resume los principios en los que se basa la actual interpretación de los cuales mencionaré el de que «los tribunales deben garantizar, mediante un examen atento (....), que la legislación federal respete los límites sustantivos establecidos por la Constitución». Esta otra sentencia puede verse en la dirección de Internet: http:// caselaw.lp.findlaw.com/scripts/getcase.pl?court=US\&vol=514\&invol=549

57 Jean-Victor LOUIS, «Les projets de constitution dans l'histoire de la construction européene», en Paul MAGNETTE (Ed.), La constitution de l'Europe, Editions de l'Université de Bruxelles, Bruselas 2000, pp. 41-52, en la p. 51 se preguntaba si tendrá algún futuro el modelo de la doble legitimidad pueblos/Estados, que se venía repitiendo en los proyectos de Constitución. 
del Estado, en particular las que tienen por objeto garantizar la integridad territorial del Estado, (...)».

En cuanto al modelo federal, la característica que me interesa resaltar no es la descentralización política ni el pluralismo institucional sino ese doble juego existente para la soberanía, única en su ámbito externo y plural en su ámbito interno, ya que en los Estados federales se admite la existencia de dos niveles de autoridades estatales, con poderes constituyentes y con una organización política completa ${ }^{56}$.

La Constitución federal, fruto del poder constituyente de un único pueblo, es la que marca las reglas de juego que deben ser acatadas por los Estados federados cuando hacen uso de su poder constituyente y simultáneamente, ese único pueblo, tiene un poder constituyente limitado por la lealtad al principio federal.

58 La asimilación de la Unión al modelo federal es una constante en la doctrina europea, por todos W. HALLSTEIN, Der unvollendete Bundesstaat: europäische Erfharungen und Erkentnisse, Econ, Düsseldorf, 1969, traducida al español como la Europa inacabada, Plaza y Janés, Barcelona 1971; L. KÜHNHARD, Europäische Union und föderale Ideee, C.H. Beck Ed., Munich 1993 o Bernard DUBEY, La répartititon des compétences au sein de l'Union européen à la lumière du féderalisme suisse. Systémes, enjeux et conséquences, Helbing \& Lichtenhahn, Bâle 2003.

59 Por todos, en la doctrina española, Javier RUIPÉREZ, La «Constitución europea» y la teoría del poder constituyente, Biblioteca Nueva, Madrid 2000, p. 111 donde señala la importancia del Pueblo (frente a los pueblos) a la hora de elaborar una Constitución.

60 La independencia de los EEMM se constata en el artículo I-60: Retirada voluntaria de la Unión

1. Todo Estado miembro, de conformidad con sus normas constitucionales, podrá decidir retirarse de la Unión Europea.

2. El Estado miembro que decida retirarse notificará su intención al Consejo Europeo. A la luz de las orientaciones del Consejo Europeo, la Unión negociará y celebrará con ese Estado un acuerdo que establecerá la forma de su retirada, teniendo en cuenta el marco de sus relaciones futuras con la Unión. Este acuerdo se negociará de conformidad con el apartado 3 del artículo III-325. El Consejo lo celebrará en nombre de la Unión por mayoría cualificada, previa aprobación del Parlamento Europeo.

3. La Constitución dejará de aplicarse al Estado de que se trate a partir de la fecha de entrada en vigor del acuerdo de retirada o, en su defecto, a los dos años de la notificación a que se refiere el apartado 2, salvo si el Consejo Europeo, de acuerdo con dicho Estado, decide por unanimidad prorrogar dicho plazo.

4. A efectos de los apartados 2 y 3, el miembro del Consejo Europeo y del Consejo que represente al Estado miembro que se retire no participará ni en las deliberaciones ni en las decisiones europeas del Consejo Europeo o del Consejo que le afecten.

La mayoría cualificada se definirá como un mínimo del $72 \%$ de los miembros del Consejo que represente a Estados miembros participantes que reúnan como mínimo el $65 \%$ de la población de dichos Estados.

5. Si el Estado miembro que se ha retirado de la Unión solicita de nuevo la adhesión, su solicitud se someterá al procedimiento establecido en el artículo I-58.

61 Luis María DÍEZ-PICAZO, «¿Qué significa ser un Estado dentro de la Unión Europea?» en Eduardo GARCÍA DE ENTERRÍA (dir.) y Ricardo ALONSO GARCÍA (subd.), La encrucijada constitucional de la Unión Europea, Cívitas, Madrid 2002, pp. 267-285, especialmente en p. 283, argumenta que a pesar de los innegables rasgos federales de la Unión el mantenimiento de atributos por parte de los Estados, inherentes a la idea misma de Estado independiente, es lo que diferencia a la Unión de las experiencias federales. Y uno de esos rasgos federales presentes en la Unión es sin duda el esgrimido por Pierre Pescatore en 1982 «Los métodos del federalismo no son únicamente una forma de organizar Estados. Parece más bien que el federalismo es una filosofía política y legal que se adapta a sí misma a todos los contextos políticos tanto en el ámbito regional como internacional, cada vez que y dondequiera que se cumplan dos requisitos previos básicos: la búsqueda de la unidad combinada con un respeto genuino por la autonomía y el interés legítimo de las comunidades diferenciadas», citado por J.H.H. WEILER, «Federalism withouth Constitutionalism: Europe's Sonderweg», en Kalypso NICOLAÏDIS y Robert HOWSE (Eds.), The federal Vision: legitimacy and levels of governance in the United States and the European Union Oxford University Press, Oxford 2001, p. 54. 
(Principios fundamentales) del proyecto, que dice en sus dos primeros números:

«1. La delimitación de las competencias de la Unión se rige por el principio de atribución $^{68}$. El ejercicio de las competencias de la Unión se rige por los principios de subsidiariedad y proporcionalidad.

2. En virtud del principio de atribución, la Unión actúa dentro de los límites de las competencias que le atribuyen los Estados miembros en la Constitución para lograr los objetivos que ésta determina. Toda competencia no atribuida a la Unión en la Constitución corresponde a los Estados miembros».

Si hasta ahora la Constitución ha constituido un Estado desde ahora constituirá además una Unión de Estados para gestionar una serie de materias en común. Por lo demás se mantendrían las características básicas de cualquier texto constitucional ${ }^{69}$ : en él se funda la legitimidad de los poderes a los que un pueblo (unos ciudadanos en este caso) se sujeta y la validez del derecho que le obliga; en él se establece el sistema de relaciones y el equilibrio entre los diversos poderes y los límites que el Derecho creado por éstos ${ }^{70}$ encuentra en los derechos que el acto constituyente proclama como fundamentales ${ }^{71}$; y en el se constituye la Unión como entidad jurídica ${ }^{72}$.

Pero, otra de las características de la Constitución del Estado social y democrático de Derecho es su normatividad ${ }^{73}$.

Mientras la ciencia política explica el fenómeno de la integración europea, fundamentalmente, a través de la teoría de la multilevel governance ${ }^{74}$, teoría que parte de la idea, en palabras de Telò ${ }^{75}$, de que la Unión está destinada a evolucionar hacia una especie de «edad media post-moderna», subsistemas cada vez más autorreferenciales, emergencia de multitud de autoridades (poderes tecnocráticos, recursos transnacionales públicos y privados, actores subnacionales, nacionales y supranacionales) que construyen un sistema de decisión

62 En este sentido, B.M. ZUPANCIC, «From combat to contract or was does the Constitution constitute?, European Review of Public Law, 1999, pp. 11-56, que resalta las diferentes visiones que existen tras una Constitución, desde la visión contractualista hasta la normativista de nuestros días; o J. C. PIRIS, «L’Unión européenne a-t-elle une constitution? Lui en faut-il-une?, Revue Trimestrielle de Droit Européen, 1999, pp. 599-635, especialmente en la p. 600 , donde da cuenta de la pluralidad semántica del término constitución: desde el ámbito material (según se ocupe de él el derecho internacional o el nacional) o desde el ámbito territorial (estemos en un Estado centralizado o federal) ....

63 En sentido análogo se expresa Jürgen SCHWARZE, «Perspectivas constitucionales de la Unión europea ante la próxima CIG de 2004», en Eduardo GARCÍA DE ENTERRÍA (dir.) y Ricado ALONSO GARCÍA (subd.), La encrucijada constitucional de la Unión Europea, Cívitas, Madrid 2002, pp. 299- 311, especialmente pp. $310-$ 311 donde señala que para evitar el fracaso hay que da tiempo para desarrollar un orden constitucional.

64 Palabras de la Resolución del Parlamento Europeo sobre la preparación de la reforma de los Tratados y de la próxima conferencia intergubernamental (C5-0143/1999/2135(COS)), de 18 de noviembre de 1999.

65 Los términos constitucionalismo y constitucionalización en la Unión Europea se refieren a la transformación de la Comunidad de ordenamiento jurídico internacional a ordenamiento jurídico constitucional, en este sentido A. STONE SWEET, «The European Court and National Courts; Doctrine and Jurisprudence» en A.-M. SLAUGTHER, A. STONE SWEET y J. H. H. WEILER (eds.), Constitutional Dialogues in the European Community, Hart Publishing, Oxford and Portland 1998, Cap. 11.

66 En el mismo sentido se expresa Araceli Mangas «Constitución europea: vino viejo en odres nuevos», en el diario La Razón, el día 28 de junio de 2004: «No es una constitución. La UE no es un estado federal por la sencilla razón de que no es un estado ni hay un pueblo europeo». 
siempre presente, fundamentalmente, por el contenido simbólico de los conceptos. Y pocas veces han sido aceptadas aquellas estrategias semánticas fundadas explícitamente en el lenguaje estatal, aunque el nuevo proyecto de Constitución rompe esta tradición empezando por su título: Constitución.

A pesar de que exista doctrina que pretende flexibilizar este concepto ${ }^{62}$, en nuestra tradición la Constitución es el acto fundador de un Estado, diríamos que es el elemento que distingue al Estado de otras formas de comunidades políticas, instituidas por tratados o por convenciones. Por eso, y para seguir con la prudencia semántica que ha caracterizado a la Unión, si pudiese elegir el término hablaría de una Carta Constitucional de la Unión Europea, ${ }^{63}$ ya que resulta igualmente efectivo para conseguir aquello para lo que se pone en marcha este proyecto: la simplificación y la racionalización de los tratados en vistas a conseguir una mayor transparencia e inteligibilidad de los ciudadanos ${ }^{64}$. En cualquier caso, si finalmente se acuña el concepto de Constitución europea, estaríamos dando un nuevo matiz al concepto de Constitución ${ }^{65}$, en la medida que ya no servirá únicamente para decir que es el acto de afirmación del poder originario de un pueblo sobre sí mismo y sobre el espacio que ocupa, ya que si existiese una Constitución europea sería la afirmación del poder originario de muchos Estados sobre ellos mismos y sobre el espacio que ocupan en común en el ámbito de unas materias tasadas en el propio texto ${ }^{66}$.

Otra de las grandes consecuencias de la Constitución europea sobre el concepto de constitución es que en Europa no existe un auténtico poder constituyente, entendido como poder previo ilimitado y total ${ }^{67}$, entre otras razones, además de la inexistencia de un pueblo, porque la Constitución europea debe su inicio a un(os) poder(es) constituido(s), los gobernantes de los Estados miembros, y éstos deben ceñirse en su redacción a los cánones de constitucionalidad de cada Estado y porque el texto constitucional sólo tiene el poder de regular las materias cedidas por los Estados, no todas, como queda recogido en el art. I-11

67 Por todos, Pedro DE VEGA, La reforma constitucional y la problemática del Poder constituyente, Tecnos, Madrid, 1985, p. 25: «En contraposición a los poderes constituidos (los gobernantes), ordenados y limitados en la Constitución, aparece (...), como poder previo ilimitado y total el poder constituyente».

68 Sobre el principio de atribución de competencias ver D. TRIANTAFYLLOU, Des compétences de attribution au domaine de la loi. Étude sur les fondements juridiques de l'activité administrative communautaire, Bruylan, Bruselas 1997.

69 Argumentos a favor de esta posición pueden encontrarse en Paul CRAIG, «Constituciones, constitucionalismo y Unión Europea» en Eduardo GARCÍA DE ENTERRÍA (dir.) y Ricardo ALONSO GARCÍA (subd.), La encrucijada constitucional de la Unión Europea, Cívitas, Madrid 2002, pp. 229-265, especialmente en pp. 245-249, donde el autor refuta las tesis en sentido contrario expuestas por D. GRIMM, «Does Europe Need a Constitution?, European Law Journal, 1, 1995, p. 282 y ss.

70 El Título III se ocupa de las competencias de la Unión, el Título IV de las instituciones de la Unión y el Título V del ejercicio de las competencias de la Unión.

71 El artículo I-9 (Derechos fundamentales) dice:

1. La Unión reconoce los derechos, libertades y principios enunciados en la Carta de los Derechos Fundamentales que constituye la Parte II.

2. La Unión se adherirá (procurará adherirse en el texto de Salónica) al Convenio Europeo para la Protección de los Derechos Humanos y delas Libertades Fundamentales. Esta adhesión no modificará las competencias de la Unión que se definen en la Constitución.

3. Los derechos fundamentales que garantiza el Convenio Europeo para la Protección de los Derechos Humanos y de las Libertades Fundamentales y los que son fruto de las tradiciones constitucionales comunes a los Estados miembros forman parte del Derecho de la Unión como principios generales.»

72 Artículo I-7: «La Unión tiene personalidad jurídica». 
asunto $A$ lsthom ${ }^{79}$, hablando de los objetivos enumerados en el antiguo art. 2 del TCEE, en concreto el que se refiere a «un desarrollo armonioso, equilibrado y sostenible de las actividades económicas», el Tribunal de Justicia sostiene que no crea obligaciones jurídicas a cargo de los Estados miembros ni crea derechos para los particulares y que, por tanto, no son susceptibles de ser invocados por éstos ante sus jurisdicciones nacionales.

Porque, en la Unión europea, el principio del efecto directo es un principio que sólo afecta a aquellas partes del Tratado que decide el Tribunal de Justicia ${ }^{80}$, un poder constituido-constituido, podríamos decir, y los criterios que ha establecido en su jurisprudencia para que lo previsto en los Tratados constitutivos pueda ser directamente aplicable a los individuos y, por tanto, pueda ser exigido por éstos, son los siguientes: 1) que esté formulado sin condiciones; 2) que sea completo en sí mismo desde una óptica jurídica; y, por ende, 3) que no precise para su cumplimiento o eficacia otros actos de los Estados miembros o de las instituciones comunitarias.

Los poderes públicos comunitarios están, por tanto, indirectamente vinculados al citado art. I-3.3, y también a los derechos sociales previstos en la Carta de Derechos, a tenor del art. II-112.1 ${ }^{81}$, siempre que tales derechos no sean fundamentales en cuyo caso se aplicará el art. II-112.4 $4^{82}$ o siempre que no sean considerados principios en cuyo caso se aplicará el art. II-112. $5^{83}$. Esta clasificación dependerá de los Estados miembros ${ }^{84}$. Y, en España aunque la jurisprudencia constitucional haya consagrado el principio de regresividad (STC 134/1987 por todas), que permite una gran disponibilidad para el legislador, comunitario o estatal, del contenido material de los derechos sociales, al menos, nunca podrán carecer de un mínimo contenido ${ }^{85}$.

\section{LA LEGITIMIDAD DEMOCRÁTICA DE LA UNIÓN EUROPEA}

Cuando la última versión del proyecto de Constitución dice en su art. 1.1:

»La presente Constitución, que nace de la voluntad de los ciudadanos y de los Estados de Europa de construir un futuro común, crea la Unión Europea»

73 Ver el interesante trabajo de Carlos DE CABO MARTÍN, La reforma constitucional desde la perspectiva de las fuentes del Derecho, Trotta, Madrid, 2003.

74 Ver el reciente trabajo de Christoph MÖLLERS, «Steps to a Tripartite Theory of Multi-level-Government», Jean Monnet Working Paper 5/03, http://www.jeanmonnetprogram.org/papers/03/030501.html

75 Mario TELÒ, «Le constitutionnalisme européen du XXe au XXIe siècle», en Paul MAGNETTE (Ed.), La constitution de l'Europe, Editions de l'Université de Bruxelles, Bruselas 2000, pp. 69-78, especialmente p. 75.

76 Como muy bien dice Vlad CONSTANTINESCO, «Estados, Naciones y Unión Europea» en Alberto PÉREZ CALVO (coord.), Estado, Nación y soberanía, Temas del Senado, Madrid 2000, pp.436-449, especialmente p. 445, « la separación horizontal de los poderes no se define verdaderamente en el esquema institucional comunitario».

77 Por todos el trabajo de Panayoties SOLDATOS, Le système institutionnel et politique des Communautés européennes dans un monde en mutation. Théorie et practique, Bruylant, Bruselas 1989, especialmente pp. 150-164, donde tras comparar el sistema institucional de la Unión con el capítulo VI del libro XI de El espíritu de las leyes de Montesquieu concluye que la entonces CEE se aproxima a dicha concepción. 
fragmentado y centrífugo, cuya consecuencia es que el espacio público pierda su unicidad. Y esta visión es todo lo contrario a la idea en la que se basan los Estados constitucionales europeos, que, como Estados sociales y democráticos de derecho, pretenden regular todo el espacio público, buscando el bienestar general, según criterios de objetividad, unicidad y generalidad.

Para los teóricos de la multilevel governance, que predican la diferenciación, la flexibilización y la fragmentación del proceso de integración, no es posible, por tanto «constituzionalizar» la Unión, normarla. Se trataría, por el contrario, de fragmentar las normas, hacer leyes microsectoriales negociadas entre las partes. En resumen, lo subjetivo crecería en importancia impregnando todo el derecho público que deviene privado por sectores y conceptos como legitimación democrática, separación de poderes ${ }^{76}$ acaban teniendo un contenido de derecho privado (participación de los interesados, diferentes centros de decisión $^{77}$ ) y no de derecho público. En resumen, cuando se habla de la debilidad del Estado lo que se está queriendo decir es debilidad de los principios constitucionales del Estado social, ya que la fragmentación de las normas produce una de-construcción del Estado constitucional. Y esto no se arregla con la existencia de leyes europeas (art. I-33.1).

Por eso, para que el texto constitucional europeo armonizase con los principios constitucionales del estado social y democrático de derecho su artículo 3, Objetivos de la Unión, debería tener un valor jurídico vinculante para todas las instituciones comunitarias. Porque en este artículo se recogen los grandes principios del Estado social (especialmente en el art.3.3 ${ }^{78}$. Y digo debería porque, a tenor de la sentencia de 24 de enero de 1991,

78 Dice el art. I-3.3:

«La Unión obrará en pro del desarrollo sostenible de Europa basado en un crecimiento económico equilibrado y en la estabilidad de los precios (no estaba en el texto de Salónica), en una economía social de mercado altamente competitiva, tendente al pleno empleo y al progreso social, y en un nivel elevado de protección y mejora de la calidad del medio ambiente. Asimismo, promoverá el progreso científico y técnico.

La Unión combatirá la exclusión social y la discriminación y fomentará la justicia y la protección sociales, la igualdad entre mujeres y hombres, la solidaridad entre las generaciones y la protección de los derechos del niño.

La Unión fomentará la cohesión económica, social y territorial y la solidaridad entre los Estados miembros.

La Unión respetará la riqueza de su diversidad cultural y lingüística y velará por la conservación y el desarrollo del patrimonio cultural europeo.»

79 Asunto C-339/89, Recopilación 1991, p. I-107

80 Por ejemplo, las disposiciones relativas a la libertad de circulación de capitales no tuvieron efecto directo, según la jurisprudencia del Tribunal de Justicia, hasta la Directiva 88/361 del Consejo, de 24 de junio de 1988 (DOCE L 178, 1988), mientras que las relativas a la libertad de circulación de los trabajadores (art. 39 del TCE) tienen dicho efecto directo desde la sentencia Van Duyn de 4 de diciembre de 1974, asunto 41/74, o las relativas a la libertad de establecimiento (art. 43 del TCE) desde la sentencia Reyners de 21 de junio de 1974, asunto 2/74, o las relativas a la libre prestación de servicios (art. 49 del TCE) desde la sentencia Van Binsbergen de 3 de diciembre de 1974 , asunto $33 / 74$.

81 1. Cualquier limitación del ejercicio de los derechos y libertades reconocidos por la presente Carta deberá ser establecida por la ley y respetar el contenido esencial de dichos derechos y libertades. Dentro del respeto del principio de proporcionalidad, sólo podrán introducirse limitaciones cuando sean necesarias y respondan efectivamente a objetivos de interés general reconocidos por la Unión o a la necesidad de protección de los derechos y libertades de los demás.

82 «En la medida en que la presente Carta reconozca derechos fundamentales resultantes de las tradiciones constitucionales comunes a los Estados miembros, dichos derechos se interpretarán en armonía con las citadas tradiciones». 
democrática de la Unión europea si se establecieran constitucionalmente las bases y los límites de este proceso y se diese una mayor participación de la ciudadanía en el mismo.

Porque, por el momento, el añadido de la voluntad de la ciudadanía, es decir, según el art. I-10.1 del proyecto de Constitución, de «toda persona que tenga la nacionalidad de un Estado miembro» — continúa el artículo diciendo "posee la ciudadanía de la Unión, que se añade a la ciudadanía nacional sin sustituirla»-, tiene, desde mi punto de vista, un efecto más estético que jurídico, en la medida en que la ciudadanía comunitaria no tiene ningún mecanismo directamente previsto para hacer conocer su voluntad y sólo puede expresarla a través de los mecanismos mediatos previstos en cada sistema constitucional ${ }^{91}$.

Tsatos $^{92}$, en cambio, entiende que existe una doble legitimidad: la de los Estados (asegurando el principio de igualdad entre Estados miembros) y la de los ciudadanos, (Unión de Estados y Unión de pueblos). Pero, desde mi punto de vista la única legitimidad estructurada es la de los Estados y, únicamente, de manera indirecta, a través de los Estados, la de los ciudadanos.

En cuanto a la segunda parte del artículo hay una mejora ostensible en la versión final, cuando se añade:

«a la que los Estados miembros confieren competencias para alcanzar sus objetivos comunes» (esta parte no figuraba en el primer borrador).

Veamos qué entiende nuestro sistema constitucional sobre éstas competencias que se confieren. La base es el Declaración del Tribunal Constitucional de 1 de julio de 1992, donde establece la distinción entre cesión de competencias y cesión del ejercicio de las mismas. Aunque, esta distinción pudo en su momento resultar artificiosa, puede explicarse a la luz del art. 60 (Retirada voluntaria de la Unión) del proyecto de Constitución, ya que

de 'competencias derivadas de la Constitución', no disponer de la Constitución misma, contrariando o permitiendo contrariar sus determinaciones, pues ni el poder de revisión constitucional es una 'competencia' cuyo ejercicio fuera susceptible de cesión ni la propia Constitución admite ser reformada por otro cauce que no sea el de su Título X, esto es, a través de los procedimientos y con las garantías allí establecidas y mediante la modificación expresa de su propio texto». Ver en este sentido, J. GERKRATH, «La critique de la legitimité démocratique de l'Union européenne selon la Cour constitutionelle fédérale de Karlsruhe», en G. DUPRAT (dir.), L'Union européenne: droit, politique, démocratie, PUF, París 1996, pp. 209-241; o J. CAPOROSO, «The European Union and Forms of State: Westphalian, Regulatory or Post-Modern», Journal of Common Market Studies, 1996, pp. 29-52, especialmente p. 48 donde señala la preeminencia del mercado sobre otros elementos políticos del Estado social.; o en la doctrina española el trabajo de Luis JIMENA QUESADA, La Europa Social y Democrática de Derecho, Dykinson, Madrid 1997.

88 Ver Luis María DÍEZ PICAZO, Constitucionalismo de la Unión Europea, Cuadernos Cívitas, Madrid 2002, pp. 121-128, bajo el epígrafe Significados jurídicos de la soberanía, especialmente p. 124.

89 Ver F. BASSANINI y Giulia TIBERI, Una Constituzione per l'Europa dalla Convenzione europea alla Conferenza Intergobernativa, Il Mulino, Bologna 2003.

90 En este sentido abría que entender la frase del Prefacio del proyecto de Tratado constitucional presentado en Salónica «impulsando la aportación de los parlamentos nacionales a la legitimidad del proyecto europeo», cuando se refiere a una de las tareas que aborda la Convención, planteadas en la Declaración de Laeken. 
en principio, soslaya todo el debate sobre la existencia o no de un pueblo europeo, y permanece fiel al método comunitario: La Unión ha sido creada por los Estados, más exactamente por el acuerdo de los gobiernos centrales de los Estados, acuerdo que ha sido ratificado en cada país según su propio sistema constitucional interno, y al descansar sobre los Estados descansa sobre la legitimidad democrática de cada Estado miembro. No es algo diferente al Estado sino una prolongación nueva, sui generis, del mismo ${ }^{86}$.

Precisamente por eso, la Unión no puede contravenir los principios constitucionales sobre los que descansa y, sólo puede aceptarse una Unión europea que respete los principios del Estado social y democrático de Derecho ${ }^{87}$.

Si tomamos como referencia el sentido que actualmente tiene el concepto de soberanía, en palabras de Díez-Picazo ${ }^{88}$, «la mera proclamación de un titular de la soberanía, a quien no corresponde el ejercicio inmediato del poder político, tiene un significado muy diferente: se limita a establecer cuál es la fuente última de legitimidad dentro de un Estado», vemos que la voluntad de los Estados está legitimada democráticamente por cada pueblo europeo, y por ende la Unión recibe, de manera mediata, su legitimación de la misma fuente. No hay pues una legitimación democrática directa de la Unión europea, ni puede haberla, si no constituimos un Estado ${ }^{89}$.

Por eso, creo que es interesante distinguir entre las fuentes de legitimidad democrática y el funcionamiento democrático posterior de la Unión, o dicho de otra manera, la legitimación de las decisiones comunitarias. Es decir, el aumento de poderes del Parlamento europeo o el acrecentamiento de sus relaciones con los Parlamentos nacionales mejoran, sin duda, el funcionamiento democrático, pero no dan un ápice más a la legitimidad democrática de la Unión ${ }^{90}$. Si se quisiera mejorar ésta los mecanismos serían otros, por ejemplo: un referéndum obligatorio en cada Estado miembro para ratificar cada nuevo tratado constitucionalmente importante o, desde otro punto de vista, la ampliación del derecho de sufragio a la ciudadanía extracomunitaria en temas europeos, o la constitucionalización en cada Estado miembro del proceso de integración. Es decir, se mejoraría la legitimidad

83 «Las disposiciones de la presente Carta que contengan principios podrán aplicarse mediante actos legislativos y ejecutivos adoptados por las instituciones, órganos y organismos de la Unión, y por actos de los Estados miembros cuando apliquen el Derecho de la Unión, en el ejercicio de sus competencias respectivas. Sólo podrán alegarse ante un órgano jurisdiccional en lo que se refiere a la interpretación y control de la legalidad de dichos actos».

84 Así se puede entender el art. II-112.6 «Se tendrán plenamente en cuenta las legislaciones y prácticas nacionales según lo especificado en la presente Carta». Acompaña al Tratado la Declaración relativa a la expolicación de la Carta de Derechos fundamentales redactada bajo la autoridad del Presidium de la Convención de la que la CIG «toma nota» y éstas explicaciones -sobre el antiguo art. 52- sobre el alcance e interpretación de los derechos y principios del art. II-112 pueden verse en http://ue.eu.int/igcpdf/es/04/cg00/cg00087-ad02re02. es04.pdf pp. 86-89.

85 Para ver la incidencia de las normas comunitarias en el contenido de los derechos sociales reconocidos en nuestra Constitución, especialmente del Pacto de estabilidad (Reglamentos 1466/97 y 1467/97) ver el trabajo de Gonzalo MAESTRO BUELGA, «El vínculo presupuestario comunitario y los derechos sociales», Revista Vasca de Administración Pública n ${ }^{\circ}$ 64, sept-diciembre 2002, pp. 193-219, donde el autor concluye que la traslación de este pacto al derecho interno actúa como un factor de erosión de la protección social (p. 219).

86 Es lo que Jean-Marc FERRY, «Le problème de la suveraineté en regard d'une union politique européenne», en Paul MAGNET'TE (Ed.), La constitution de l'Europe, Editions de l'Université de Bruxelles, Bruselas 2000, pp. 53-68, especialmente p. 62, denomina una especie de soberanía estatal supranacional.

87 Así debe ser entendida la sentencia sobre Maastricht del Tribunal Constitucional alemán, ya que muchos de sus argumentos tienen su base en la defensa de dichos principios, y también la Declaración del Tribunal Constitucional español de 1 de julio de 1992, cuando afirma que las Cortes pueden «ceder o atribuir el ejercicio 
lantes, mientras que los Estados miembros, en cuanto tales, únicamente podrán hacerlo si son facultados por la Unión o para aplicar actos de la Unión».

Pero qué pasa cuando el derecho de las instituciones comunitarias es contrario a un principio constitucional. Porque la atribución de competencias que se hace a la Unión es, de entrada, considerando que ésta respetará los principios constitucionales de los Estados miembros ${ }^{95}$. Aunque ningún Estado pueda regular autónomamente la materia siempre puede pedir al Tribunal de Justicia que anule la norma por no adecuarse a alguno de los valores del art. I-2, aunque más fácil resultaría si la Constitución española previese esa posibilidad $^{96}$.

En el resto de las categorías de competencias ${ }^{97}$, la Kompetenz-Kompetenz pertenece a los Estados miembros, aunque su ejercicio esté supeditado a lo que establezca la Carta constitucional de la Unión ${ }^{98}$. Y, precisamente de este reparto de competencias le viene su legitimidad al Tribunal de Justicia y por eso puede ser el intérprete supremo del derecho comunitario, en el ámbito de las competencias atribuidas (art. I-29.1).

Resumiendo lo dicho hasta el momento, la legitimidad democrática de la Unión tiene la misma fuente que la de cada Estado que la compone y es reconocida de una manera indirecta cuando se habla de la voluntad de los ciudadanos de Europa.

Los Estados constitucionales europeos han decidido crear la Unión Europea, a la que atribuyen una serie de competencias para que se gestionen en común. Y, dada la trascendencia de tal momento, sería jurídicamente deseable que las Constituciones de los Estados miembros hablasen de esto, regulando las relaciones con la Unión para así cerrar convenientemente el tan oído déficit de constitucionalidad, que, desde mi punto de vista, tiene mucho más que ver con las carencias de los sistemas constitucionales de los EEMM que con cualquier aspecto de los tratados comunitarios.

Y una previsión constitucional clara es mucho más necesaria, si se tiene en cuenta que en el actual proyecto constitucional también se mantiene la llamada cláusula de flexibilidad, en el art. I-18.1:

«Cuando se considere necesaria una acción de la Unión en el ámbito de las políticas definidas en la Parte III para alcanzar uno de los objetivos fijados por la Constitución, sin que ésta haya previsto los poderes de actuación necesarios a tal efecto, el Consejo de Ministros adoptará las medidas adecuadas por unanimidad, a propuesta de la Comisión

91 En la doctrina, ya Antonio La PERGOLA, «نPara qué una Constitución en la Unión europea?» en M. OREJA AGUIRRE (dir.), La Constitución europea, Universidad Complutense, Madrid 1994, pp. 43-51, especialmente pp. 47-48, señalaba que la Constitución de la Unión no debe tener las mismas características de una estatal y estaba motivada por la existencia de una colectividad democrática de ciudadanos.

92 Dimitris Th. TSATOS, «Die Europäische Unionsgrundordnung im Schatten der Effektivitätsdiskussion», Jabrbuch für das öffentliche Recht, vol. 49, 2001, pp. 63-78, especialmente pp. 66-67, este autor entiende que precisamente en eso estriba la mayor dificultad para aplicar los conceptos clásicos del federalismo en el ámbito comunitario.

$93 \mathrm{Ha}$ desaparecido en la versión final el punto dos que acompañaba a este precepto: Los Estados miembros adoptarán todas las medidas generales o particulares apropiadas para asegurar el cumplimiento de las obligaciones derivadas de la Constitución o resultantes de los actos de las instituciones de la Unión». Aunque se ha añadido una declaración en la que se especifíca que el valor de este artículo es el conocido hasta ahora, es decir, «refleja la jurisprudencia del Tribunal de Justicia de las Comunidades Europeas y del Tribunal de Primera Instancia». 
los Estados miembros de la Unión mantienen en todo momento su independencia para abandonarla, por lo que, realmente parece que se cede el ejercicio de la competencia.

Para articular este camino y dirimir a quien pertenece la Kompetenz-Kompetenz habría que distinguir dos momentos: en el primero, antes de la ratificación de un tratado, la Kompeten -Kompeten z pertenece a cada Estado miembro, pero en el segundo, una vez atribuida la materia, la Unión pasará a tenerla, porque en las materias atribuidas los EEMM ya no tienen posibilidades autónomas de acción, como bien señala el art. I-6 (Derecho de la Unión):

«La Constitución y el Derecho adoptado por las instituciones de la Unión en el ejercicio de las competencias que se le atribuyen a ésta primarán sobre el Derecho de los Estados miembros» $)^{33}$.

Y en este aspecto la jurisprudencia del Tribunal de Justicia ha dejado clara la normatividad de los Tratados, ya que a la hora de desarrollar las materias atribuidas los principios constitucionales no pueden ser suspendidos por acuerdos informales entre los EEMM ${ }^{94}$, ni siquiera usando la unanimidad en el Consejo. Ahora bien, esto sólo sucede de manera absoluta con las competencias exclusivas, mientras los EEMM sigan perteneciendo a la Unión, como se establece en el art. I-12.1:

«Cuando la Constitución atribuya a la Unión una competencia exclusiva en un ámbito determinado, sólo la Unión podrá legislar y adoptar actos jurídicamente vincu-

94 Asuntos 90 y 91/63, Comisión, Bélgica y Luxemburgo, Rec. 1964, pp. 1329 y 1345; Asunto 43/75, Défrenne, Rec. 1976, pp. 45 y ss.; asunto 59/75, Manghera, Rec. 1976, p. 91.

95 Como dice Miguel AZPITARTE SÁNCHEZ, «Las relaciones entre el Derecho de la Unión y el Derecho del Estado a la luz de la Constitución Europea» en Revista de Derecho Constitucional Europeo, no $1 / 2004$ en http://www.ugr.es/ redce/ReDCE1/ReDCEsumario1.htm «cabe concluir tentativamente que el problema de la primacía queda en suspenso».

96 En análogo sentido se expresa el Consejo de Estado su Dictamen relativo al Tratado por el que se establece la Constitución Europea de 21 de octubre de 2004»: «Cabe apuntar que una fórmula para salvar en este caso y pro futuro eventuales problemas de compatibilidad entre la Constitución y el Derecho comunitario, quizás mejor que proceder a reformas materiales puntuales cada vez que se detecte una colisión, sería, siguiendo la pauta de otros modelos constitucionales europeos, introducir en la propia Constitución (a.e. con una reformulación del artículo 93) una cláusula de integración que incorpore un mecanismo que por sí solo y en sí mismo permita -con los límites de intangibilidad que se estimen irrenunciables, con los objetivos o con los requisitos formales agravados que se consideren necesarios- una apertura general del ordenamiento español al Derecho comunitario y, en su virtud, se reconozca apriorísticamente la constitucionalidad —la compatibilidad con la Constitución - de dicho ordenamiento. Si, en su caso, fuera necesaria una reforma constitucional que permita una articulación ajustada entre el Tratado de referencia y la Constitución, cabría plantearse además — como también se ha hecho en otros Estados miembros de la Unión Europea- la conveniencia de aprovechar la ocasión para dar cauce a otra cuestión, si no necesaria, conveniente, cual sería la de «europeizar» en alguna medida la Constitución española. En su texto vigente no existe ninguna mención expresa a la Unión Europea (o a las Comunidades que constituyen su origen), producto sin duda de las circunstancias del periodo constituyente. No hay referencia alguna al fenómeno de la integración europea ni en el plano teleológico (como objetivo de la Nación española) ni en el plano estructural (España como Estado miembro) ni en el ámbito normativo-ordinamental (sin perjuicio de la referencia implícita del artículo 93) ni en cuanto a las implicaciones competenciales que la pertenencia a la Unión supone para la organización política (tanto respecto de poderes del Estado y órganos constitucionales como en cuanto a la estructura territorial)». Ver http://www.boe.es/g/es/iberlex/bases_datos_ce/doc.php?coleccion=ce\&id=2004-2544 
trol es formal — propuesta de la Comisión, aprobación del Parlamento Europeo, unanimidad del Consejo de Ministros_ y material — control de los parlamentos nacionales para asegurar que se cumplan los principios de subsidiariedad y proporcionalidad ${ }^{108}$ (art. I-18.2) y prohibición de armonizar disposiciones legislativas y reglamentarias de los EEMM si la Constitución excluye dicha armonización (art. I-18.3)

Mientras que en EEUU no hay ningún control formal extraordinario previo a la norma, sí que encontramos controles materiales que, en el caso de no ser tenidos en cuenta por el legislador federal, supondrán una declaración de inconstitucionalidad posterior por parte del Tribunal Supremo ${ }^{109}$. Este control material descansa en los siguientes principios:

- La ambigüedad y la desproporcionalidad no pueden jugar a favor del poder federal (Sentencia Gregory v. Ascroft 1991 — 501 U.S. 452- y Sentencia City of Borne v. Flores 1997 - 521 U.S. 507- ${ }^{110}$ );

- La doctrina del anti-commandering tanto legislativo (New York v. United States 1992 — 505 U.S. $144{ }^{111}$ ) como ejecutivo (Printz v. United States 1997 ${ }^{112}$ ), es decir, el Congreso no puede ordenar la actuación de los parlamentos o de los gobiernos estatales; Si considera que un asunto debe ser regulado por una norma federal será la administración federal la que se encargue de ejecutarla ${ }^{113}$ — esta doctrina se utiliza también respecto a las obligaciones internacionales de los EEUU ${ }^{114}$-;

- La Federación no puede aprobar leyes que reconozcan un derecho de reclamación de los ciudadanos contra los Estados según la doctrina de la «inmunidad soberana» de la enmienda XI: «El poder judicial de los Estados Unidos no debe

$97 \mathrm{El}$ art. I-14 regula las competencias compartidas, el art. I-15, la coordinación de políticas económicas y de empleo, el art. I-16 la política exterior y de seguridad común y el art. I-17, los ámbitos de la acción de apoyo, coordinación y complemento.

98 Es decir lo establecido en el art. I-12:

«2. Cuando la Constitución atribuya a la Unión una competencia compartida con los Estados miembros en un ámbito determinado, la Unión y los Estados miembros podrán legislar y adoptar actos jurídicamente vinculantes en dicho ámbito. Los Estados miembros ejercerán su competencia en la medida en que la Unión no haya ejercido la suya o haya decidido dejar de ejercerla.

3. Los Estados miembros coordinarán sus políticas económicas y de empleo según las modalidades establecidas en la Parte III, para cuya definición la Unión dispondrá de competencia.

4. La Unión dispondrá de competencia para definir y aplicar una política exterior y de seguridad común, incluida la definición progresiva de una política común de defensa.

5. En determinados ámbitos y en las condiciones establecidas en la Constitución, la Unión dispondrá de competencia para llevar a cabo acciones con el fin de apoyar, coordinar o completar la acción de los Estados miembros, sin por ello sustituir la competencia de éstos en dichos ámbitos.

Los actos jurídicamente vinculantes de la Unión adoptados en virtud de las disposiciones de la Parte III relativas a esos ámbitos no podrán conllevar armonización alguna de las disposiciones legales y reglamentarias de los Estados miembros (se ha añadido en la versión de la CIG).

6. El alcance y las condiciones de ejercicio de las competencias de la Unión se determinarán en las disposiciones de la Parte III relativas a cada ámbito».

Armin VON BOGDANDY y Jürgen BAST, «El orden competencial vertical de la Unión Europea: contenido y perspectivas de reforma», en Eduardo GARCÍA DE ENTERRÍA (dir.) y Ricado ALONSO GARCÍA (subd.), La encrucijada constitucional de la Unión Europea, Cívitas, Madrid 2002, pp. 19-67 hacen un estudio de cada tipo de competencia, otro estudio general puede verse en D. DITTERT, Die ausschliesslichen Konpetenzen der Europäischen Gemeinschaft im System des EG-Vertrages, Peter Lanf, Frankfurt a. M., 2001. 
Europea y previa aprobación del Parlamento Europeo».

Aunque la previsión que acompaña a ésta, de participación de los parlamentos nacionales en un momento como éste esté bien ${ }^{99}$, no es suficiente. Porque ¿hasta dónde puede la Unión incrementar sus competencias sin una base constitucional ${ }^{100}$ ?

Esta cláusula de flexibilidad ha sido comparada en nuestra doctrina a la cláusula de comercio de la Constitución de los Estados Unidos ${ }^{101}$, por eso me parece interesante precisar la actual interpretación que dicha cláusula tiene en la jurisprudencia del Tribunal Supremo americano.

El poder constituyente en EEUU lo tiene el Pueblo de los Estados Unidos ${ }^{102}$ mientras que la Unión europea, como hemos visto, nace de la voluntad constituyente de dos sujetos previamente constituidos: los Estados y los ciudadanos de Europa. Y esta calidad de poderes constituidos hace que ambos sujetos estén limitados a la hora de ejercer este poder constituyente por las Constituciones que los han creado ${ }^{103}$. Esta característica de poder constituyente derivado se manifiesta tanto en las condiciones exigidas para la entrada en vigor del Tratado constitucional como en las condiciones exigidas para su modificación ${ }^{104}$, así como en el respeto a la identidad e integridad de los EEMM ${ }^{105}$ y en la posibilidad de que un Estado abandone la Unión (art. I-60.1). Pero cuando nos ocupamos de la gestión de competencias no expresamente atribuidas por el texto constitucional a la Federación — la cláusula de comercio de la sección 3.8 del art. 1 de la Constitución ${ }^{106}$ — o a la Unión — la cláusula de flexibilidad del art. I-18 del Tratado constitucional ${ }^{107}$ — veremos que la soberanía residual de los estados americanos frente a la federación no es nada desdeñable.

En la Unión, la cláusula de flexibilidad, además del control posterior del Tribunal de Justicia, va acompañada de un control previo a la entrada en vigor de la norma. Este con-

99 Dice el art. I-18.2: «La Comisión Europea, en el marco del procedimiento de control del principio de subsidiariedad mencionado en el apartado 3 del artículo I-11, indicará a los parlamentos nacionales las propuestas que se basen en el presente artículo».

100 Es interesante recordar que la flexibilidad fue objeto de reflexión en la sentencia sobre Maastricht del Tribunal Constitucional alemán. El contenido de la misma, en cuanto a esta materia se refiere, es perfectamente analizado por Jorge AGUACIL GONZÁLEZ-AURIOLES, La directiva comunitaria desde la perspecticva constitucional, CEPC, Madrid 2004, pp. 81-89.

101 Por todos, Eduardo GARCÍA DE ENTERRÍA, «El Proyecto de Constitución Europea», Revista Española de Derecho Constitucional, no 45/1995, pp. 9-29, especialmente pp. 26-27.

102 Puede consultarse en http://www.georgetown.edu/pdba/Constitutions/USA/usa1787.html

103 La Constitución europea recoge algunos de estos principios en su art. I-2 como valores de la Unión: respeto a la dignidad humana, libertad, democracia, igualdad, Estado de Derecho y respeto a los derechos humanos, incluidos los derechos de las personas pertenecientes a minorías (incluido por la CIG). Estos valores son comunes a los Estados miembros en una sociedad caracterizada por el pluralismo, la no discriminación, la tolerancia, la justicia, la solidaridad y la igualdad entre mujeres y hombres (incluido por la CIG).

104 Mientras en la Unión Europea la entrada en vigor exige la ratificación de todos los EEMM, art. IV-447, en EEUU basta con: «La ratificación por las convenciones de nueve Estados bastará para que esta Constitución entre en vigor por lo que respecta a los Estados que la ratifiquen» (art. 7) —3/4 de los 13-; ahora bien en Europa hay una Declaración al Acta final en la que simplemente se prevé una posibilidad, sin darle consecuencias jurídicas, cuando la ratifiquen 4/5 partes (20 Estados): «El Consejo Europeo tomará conocimiento de la cuestión».

En cuanto a la reforma de la Constitución: Mientras el art. 5 de la Constitución de los EEUU establece un sistema de mayorías: 2/3 partes de ambas Cámaras del Congreso o de las legislaturas de los Estados para la iniciativa, en el caso europeo, se prevén tres tipos de procedimientos de revisión y en el ordinario el art. IV-443.1 da la iniciativa a cualquier EM, al PE o a la Comisión y se necesita, según el art. IV-443.2 la mayoría simple del Consejo Europeo tras consulta al PE y a la Comisión, para poner en marcha el procedimiento de reforma, a través de una 
una superabundancia de representación: electos municipales, regionales, nacionales y europeos; representantes de los trabajadores, de los empresarios, de intereses sectoriales concretos se esfuerzan en hacer valer sus intereses; los ciudadanos pueden intervenir en cualquier fase de una decisión europea, directamente o a través de sus representantes pero, como ya he apuntado antes, si la existencia de diferentes centros de poder no supone que exista una separación de poderes, tampoco la presencia de muchas voces crea necesariamente un sistema democrático.

Sin entrar en el estudio del sistema institucional comunitario ni en el aumento del número de materias en las que se acrecienta el poder de intervención del Parlamento Europeo, ni en otros temas relacionados como la transparencia o la motivación de las decisiones, me voy ocupar de las novedades de impulso democrático, relacionadas más directamente con la creación de un sistema democrático, que presenta el proyecto de Constitución y me ceñiré fundamentalmente a tres: 1) la iniciativa legislativa concedida a la ciudadanía comunitaria; y 2) la participación de los parlamentos nacionales en el proceso de decisión; y 3) la participación de las regiones.

Convención o de una Conferencia de los representantes de los Gobiernos de los Estados miembros, cuando la reforma no sea importante

La ratificación de la reforma necesita las 3/4 partes de las legislaturas de los Estados o convenciones para la ratificación en EEUU y la ratificación de todos los EEMM en la Unión (art. IV-444.3), aunque se abre una vía sin previsiones jurídicas previas para el caso de que se haya ratificado por 4/5 partes de los EEMM: el Consejo Europeo examinará la cuestión. (art. IV-444.4).

105 Art. I-5.1: La Unión respetará la igualdad de los Estados miembros ante la Constitución (introducido por la $(I G$ ), así como su identidad nacional, inherente a las estructuras fundamentales políticas y constitucionales de éstos, también en lo referente a la autonomía local y regional. Respetará las funciones esenciales del Estado, especialmente las que tienen por objeto garantizar su integridad territorial, mantener el orden público y salvaguardar la seguridad nacional.

La Constitución de los EEUU es más flexible ya que la $3^{\text {a }}$ sección 1 del art. 4 prevé: El Congreso podrá admitir nuevos Estados a la Unión, pero ningún nuevo Estado podrá formarse o erigirse dentro de los limites de otro Estado, ni un Estado constituirse mediante la reunión de dos o más Estados o partes de Estados, sin el consentimiento de las legislaturas de los Estados en cuestión, así como del Congreso.

106 Para reglamentar el comercio con las naciones extranjeras, entre los diferentes Estados y con las tribus indias.

107 «Cuando se considere necesaria una acción de la Unión en el ámbito de las políticas definidas en la Parte III para alcanzar uno de los objetivos fijados por la Constitución, sin que ésta haya previsto los poderes de actuación necesarios al efecto...».

$108 \mathrm{El}$ art. 6 del Protocolo sobre aplicación de los principios de subsidiariedad y proporcionalidad señala que en el plazo de seis semanas dictamen motivado a los Presidentes del PE, Consejo de Ministros y Comisión que exponga las razones por las que la propuesta no se ajusta al principio de subsidiariedad y señala que «Incumbirá a cada parlamento nacional o cada cámara de un parlamento nacional consultar, cuando proceda, a los parlamentos regionales que posean competencias legislativas» (in fine). En el párrafo $2^{\circ}$ del artículo 7 , se dice que tienen dos votos los parlamentos unicamerales y un voto cada cámara en los bicamerales; y en el párrafo $3^{\circ}$ del mismo artículo se precisa que si hay un tercio de votos en contra (ahora 17) «el proyecto deberá volverse a estudiar -»La Comisión deberá volver a estudiar su propuesta» decía el proyecto de la Convención. El umbral es de una cuarta parte (13) para un proyecto que tenga como base el art. III-264 de la Constitución, relativo al espacio de libertad seguridad y justicia. Aunque según el párrafo $4^{\circ}$ del art. 7 la Comisión y el resto de instituciones pueden mantener la propuesta, tras este nuevo estudio, siempre de forma motivada, el artículo 8 deja claro que el parlamento nacional puede ir al Tribunal de Justicia, a través de su gobierno por incumplimiento del principio de subsidiariedad. 
interpretarse que se extiende a cualquier litigio de derecho estricto o de equidad que se inicie o prosiga contra uno de los Estados Unidos por ciudadanos de otro Estado o por ciudadanos o súbditos de cualquier Estado extranjero». Esta jurisprudencia se estableció en la sentencia Seminole Tribe v. Florida $1996^{115}$ — 517 U. S. 44-, continuó en Alden v. Maine 1999 y Federal Maritime Com'n v. South Carolinaports Authority $2002^{116}$.

Como vemos esta última característica es exactamente contraria a lo expuesto por el Tribunal de Justicia europeo en su sentencia de 19 de noviembre de 1991, Francovich y Bonifacci, asuntos C-6/90 y C-9/90 sobre la responsabilidad de los Estados miembros por los daños ocasionados a los particulares en sus derechos por el incumplimiento del derecho comunitario, que éstos pueden hacer valer directamente ante sus tribunales nacionales ${ }^{117}$.

El modo comunitario es más estricto que el federal en sus controles formales previos a la entrada en vigor de la norma, pero no tiene tantos controles materiales, por eso no estaría de más que fuesen los propios textos constitucionales los que fijasen los límites materiales a la aplicación del art. I-18.

\section{LA LEGITIMACIÓN DEMOCRÁTICA DE LAS DECISIONES DE LA UNIÓN}

Si ya he analizado la fuente de legitimidad democrática mediata de la Unión, ahora toca ver si el funcionamiento comunitario entra dentro de los cánones de un sistema democrático. Porque como dice Magnette ${ }^{118}$, en la Unión, en lugar de déficit democrático hay

109 La interpretación que ha hecho el TS ha ido variando en el tiempo, y actualmente es restrictiva, desde US v. Lopez de 1997 (514 U.S. 549)

-http://caselaw.lp.findlaw.com/scripts/getcase.pl?court=us\&vol=514\&invol=549_, pasando por City of Borne v. Flores 1997

-http://caselaw.lp.findlaw.com/cgi-bin/getcase.pl?court=us\&navby=case\&vol=521\&invol=507 y US v. Morrison 2000

-http://caselaw.lp.findlaw.com/cgi-bin/getcase.pl?court=US\&navby=case\&vol=000\&invol=99-5-. Un estudio más detallado de las sentencias que aquí se citan puede verse en Manuel BALLBÉ Y Roser MARTÍNEZ, Soberanía dual y constitución integradora, Ariel Derecho, Barcelona 2003.

110 Ver http://caselaw.lp.findlaw.com/scripts/getcase.pl?court=us\&vol=501\&invol=452 y http:// caselaw.lp.findlaw.com/cgi-bin/getcase.pl?court=us\&navby=case\&vol=521\&invol=507, respectivamente.

$111 \mathrm{http}: / /$ caselaw.lp.findlaw.com/scripts/getcase.pl? court=US\&vol=505\&invol=144

112 http://caselaw.lp.findlaw.com/cgi-bin/getcase.pl?court=us\&navby $=$ case\&vol=521\&invol $=898$

113 Precisamente la ausencia de una administración comunitaria será la que posibilite en la Unión el nacimiento de los principios de primacía y efecto directo del derecho comunitario.

114 Ya se vio en las sentencia Bread v. Greene 1998 - http://caselaw.lp.findlaw.com/cgi-bin/getcase.pl?court $=\mathrm{US} \&$ navby $=$ case\&vol $=000 \&$ invol $=97-8214$ y se ha vuelto a constatar cuando el Tribunal internacional de justicia ha condenado a Estados Unidos por incumplir el art. 36 de la Convención de Viena sobre las relaciones consulares de 24 de abril de 1963. Primero en la sentencia Federal Republic of Germany v. US de 27 de junio de 2001, Lagrand, http://212.153.43.18/icjwww/idocket/igus/igusframe.htm y después en la sentencia México v. US de 31 de marzo de 2004 Avena et autres ressortissants mexicains http://212.153.43.18/cijwww/cdocket/cmus/cmusframe.htm.

115 http://caselaw.lp.findlaw.com/scripts/getcase.pl?court=us\&vol=517\&invol=44. Un comentario sobre las consecuencias de esta sentencia en Marcos CRIADO y Antonio DE CABO, «La actualidad constitucional en Estados Unidos en 2000», Teoría y Realidad Constitucional, nº 7, 2001, especialmente pp. 334-336. 
de que los Parlamentos nacionales controlen la actividad legislativa comunitaria, cuando en su artículo 6 dice:

«Todo Parlamento nacional o toda cámara de uno de estos Parlamentos podrá, en un plazo de seis semanas a partir de la fecha de transmisión de un proyecto de acto legislativo europeo ${ }^{124}$, dirigir a los Presidentes del Parlamento Europeo, del Consejo y de la Comisión un dictamen motivado que exponga las razones por las que se considera que el proyecto no se ajusta al principio de subsidiariedad. Incumbirá a cada Parlamento nacional o a cada cámara de un Parlamento nacional consultar, cuando proceda, a los Parlamentos regionales que posean competencias legislativas».

Estos dictámenes se harán llegar a la institución que propone la medida legislativa y, sigue diciendo el art. 7:

«El Parlamento Europeo, el Consejo y la Comisión, así como, en su caso, el grupo de Estados miembros, el Tribunal de Justicia, el Banco Central Europeo o el Banco Europeo de Inversiones, si el proyecto de acto legislativo tiene su origen en ellos, tendrán en cuenta los dictámenes motivados dirigidos por los Parlamentos nacionales o cualquiera de las cámaras de un Parlamento nacional.

Cada Parlamento nacional dispondrá de dos votos, repartidos en función del sistema parlamentario nacional. En un sistema parlamentario nacional bicameral, cada una de las dos cámaras dispondrá de un voto.

Cuando los dictámenes motivados sobre el no respeto del principio de subsidiariedad por parte de un proyecto de acto legislativo europeo representen al menos un tercio del total de votos atribuidos a los Parlamentos nacionales de conformidad con el segundo párrafo, el proyecto deberá volverse a estudiar. Este umbral será una cuarta parte cuando se trate de un proyecto de acto legislativo europeo presentado sobre la base del articulo III-264 de la Constitución relativo al espacio de libertad, seguridad y justicia.

Tras este nuevo estudio, la Comisión o, en su caso, el grupo de Estados miembros, el Parlamento Europeo, el Tribunal de Justicia, el Banco Central Europeo o el Banco Europeo de Inversiones, si el proyecto de acto legislativo europeo tiene su origen en ellos, podrá decidir mantener el proyecto, modificarlo o retirarlo. Esta decisión deberá motivarse.

Aunque se puede mantener una propuesta que cuente con el rechazo de un tercio de los parlamentos nacionales, ya veremos si se hace, teniendo en cuenta que los parlamentos nacionales obtienen legitimidad para presentar un recurso por incumplimiento del principio de subsidiariedad, que será tramitado por su gobierno, según el artículo 8 del Protocolo sobre la aplicación de los principios de subsidiariedad y proporcionalidad ${ }^{125}$.

$116 \mathrm{http}: / /$ caselaw.lp.findlaw.com/cgi-bin/getcase.pl?court=US\&navby $=$ case\&vol=000\&invol=98-436 y http:/ / caselaw.lp.findlaw.com/cgi-bin/getcase.pl? court $=U S \&$ navby $={ }_{\text {case } \& v o l=000 \& i n v o l}=01-46$

117 Como dicen Marcos CRIADO y Antonio DE CABO, «La actualidad constitucional en Estados Unidos en 1999», Teoría y Realidad Constitucional, n 5, 2000, p. 280: en el sistema de los EEUU, «no deja de ser sorprendente (...) que frente a violaciones de derechos concedidos, nadie (ni Federación ni Estado) responde.»

118 Paul MAGNETTE, «Le Principe démocratique au-delà de la représentation» en Paul MAGNETTE (Ed.), La constitution de l'Europe, Editions de l'Université de Bruxelles, Bruselas 2000, pp. 135-150, especialmente p. 148. 
1) La iniciativa legislativa popular está prevista en el Título VI de la Parte I del proyecto (»De la vida democrática de la Unión), más concretamente en su art. I-47.4 ${ }^{119}$ :

«Un grupo de al menos un millón de ciudadanos de la Unión, que sean nacionales de un número significativo de Estados miembros, podrá tomar la iniciativa de invitar a la Comisión, en el marco de sus atribuciones, a que presente una propuesta adecuada sobre cuestiones que estos ciudadanos estimen que requiere un acto jurídico de la Unión para los fines de la aplicación de la Constitución. La ley europea establecerá las disposiciones relativas a los procedimientos y condiciones necesarios para la presentación de esta iniciativa ciudadana, incluido el número mínimo de Estados miembros de los que deben proceder los ciudadanos que la presenten».

2) La participación de los parlamentos nacionales en el proceso de decisión está prevista en el Anexo 1 (Protocolo sobre el papel de los parlamentos nacionales en la Unión europea ${ }^{120}$ ), que recoge dos principios: información a los parlamentos nacionales de la actividad comunitaria y cooperación con ellos en dicha actividad. Además el art. I-46.2 (Principio de democracia representativa) del Título VI de la Parte I recuerda que:

«Los ciudadanos estarán directamente representados en la Unión a través del Parlamento Europeo.

Los Estados miembros estarán representados en el Consejo Europeo por su Jefe de Estado o de Gobierno y en el Consejo por sus Gobiernos, que serán democráticamente responsables, bien ante sus Parlamentos nacionales, bien ante sus ciudadanos» ${ }^{121}$.

Es interesante recordar que en la Sentencia sobre Maastricht de 12 de octubre de 1993, el Tribunal Constitucional alemán dejó claro que el principio democrático debe quedar asegurado en la Unión, y que la legitimación democrática de sus decisiones incumbe, en principio, a los pueblos de los Estados a través de sus Parlamentos nacionales, ya que la legitimación democrática que puede dar el Parlamento Europeo es, únicamente, complementaria, de apoyo.

Los planteamientos del Bundesverfassungsgericht que, como todos los planteamientos constitucionalistas sobre la Unión, tuvieron grandes críticas en su momento ${ }^{122}$, han tenido eco en el proyecto de Constitución y, específicamente el anexo II (Protocolo sobre la aplicación de los principios de subsidiariedad y proporcionalidad ${ }^{123}$ ), prevé la posibilidad

119 El resto del artículo I-47 constitucionaliza la práctica habitual:

1. Las instituciones de la Unión darán a los ciudadanos y a las asociaciones representativas, por los cauces apropiados, la posibilidad de expresar e intercambiar públicamente sus opiniones en todos los ámbitos de actuación de la Unión.

2. Las instituciones mantendrán un diálogo abierto, transparente y regular con las asociaciones representativas y la sociedad civil.

3. Con objeto de garantizar la coherencia y la transparencia de las acciones de la Unión, la Comisión mantendrá amplias consultas con las partes interesadas.

120 Puede encontrarse en http://ue.eu.int//igcpdf/es/04/cg00/cg00087-ad01re01.es04.pdf

121 Se mejora la redacción del texto presentado por la Convención que decía: Los Estados miembros estarán representados en el Consejo Europeo y en el Consejo por sus gobiernos, que serán responsables ante los parlamentos nacionales elegidos por sus ciudadanos», por lo que se prohibía un sistema presidencialista, o dicho de otra manera, sólo visualizaba sistemas parlamentarios. 
consultas. Estas consultas deberán tener en cuenta, cuando proceda, la dimensión regional y local de las acciones previstas. En casos de urgencia excepcional, la Comisión no procederá a estas consultas. Motivará su decisión en su propuesta ${ }^{129}{ }_{\text {» }}$

Se mantiene la posibilidad de las regiones de participar en el Consejo, representando al Estado al que pertenecen, ya que el art. I-23. 2 dice que:

«El Consejo está compuesto por un representante de cada Estado miembro, de rango ministerial, facultado para comprometer al Gobierno del Estado miembro al que represente y para ejercer el derecho al voto» ${ }^{130}$.

Siguen formando parte del Comité de las Regiones, que según el art. I-32.2 «estará compuesto por representantes de los entes regionales y locales que sean titulares de un mandato electoral en un ente regional o local, o que tengan responsabilidad política ante una asamblea elegida», y ejerce funciones consultivas, según el art. I-32.1.

Otra reivindicación regional conseguida es que el Comité de las Regiones ve por fin reconocida su legitimidad para recurrir ante el Tribunal de Justicia contra los actos legislativos en cuya materia deba ser consultado según consta en el artículo 8 , párrafo $2^{\circ}$ del Protocolo sobre la aplicación de los principios de subsidiariedad y proporcionalidad ${ }^{131}$.

Pero, la reivindicación más importante de las Asambleas legislativas de las regiones con competencias legislativas ${ }^{132}$, que han formado la Conferencia de las Asambleas Legislativas Regionales de Europa (CALRE ${ }^{133}$ ), la de asociarse a la COSAC ${ }^{134}$, formada por los Parlamentos nacionales ${ }^{135} \mathrm{y}$, por ende, tener presencia en el proceso de toma de decisiones, ha quedado fuera del proyecto de Constitución. Y eso a pesar de que el 56,3\% de la población europea vive en una región con poder legislativo y no todos los Estados cuentan con parlamentos en los que tienen presencia estas regiones como tales.

$\mathrm{Al}$ no haber previsiones directas ${ }^{136}$, esta participación queda en manos de los Estados miembros (»Incumbirá a cada parlamento nacional o a cada cámara de un parlamento nacional consultar, cuando proceda, a los parlamentos regionales que posean competencias legislativas» dice el apartado 5, in fine, del Protocolo sobre la aplicación de los principios de subsidiariedad y proporcionalidad) y, por tanto, en España, podría crearse un mecanismo que permitiese a los parlamentos autonómicos hacer valer sus competencias, al menos ante el Senado. Es decir, no estaría mal que el Senado se convirtiese en la Cámara de las Autonomías y recuperase su función de Cámara territorial.

122 Normalmente cuando los constitucionalistas critican las bases jurídicas de la Unión suelen ser tachados de «nacionalistas» o «involucionistas» y esa fue la gran crítica que recibió esta sentencia, por todos J.H.H. WEILER, «Der Staat über alles. Demos, Telos und die Maastricht-Entscheidung des Bundesverfassungsgerichts», Working Papers Harvard Law School Programs, The Jean Monnet Chair, Harvard 1995, http://www.jeanmonnetprogram.org/papers/index.html

123 Además de en este Protocolo existen referencias internas en el texto del tratado constitucional a los parlamentos nacionales (arts I-11.3, I-18.2, 24, I-42.2, I-46.2, I-58.2; III-259, III-260, III-261, III-273.1, III.276.2; y IV-443.1 y 2, IV-444.3) y otro Protocolo sobre el cometido de los Parlamentos nacionales en la Unión europea.

124 El protocolo sobre la función de los parlamentos nacionales en la Unión europea en su art. 2, prfo. $2^{\circ}$ establece que "A los efectos del presente Protocolo, se entenderá por "proyecto de acto legislativo europeo» las propuestas de la Comisión, las iniciativas de un grupo de Estados miembros, las iniciativas del Parlamento Europeo, las peticiones del Tribunal de Justicia, las recomendaciones del Banco Central Europeo y las peticiones del Banco Europeo de Inversiones, destinadas a la adopción de un acto legislativo europeo». En el proyecto de la Convención únicamente se hablaba de «propuesta legislativa de la Comisión». 
El art. 6 del Protocolo sobre sobre el papel de los parlamentos nacionales en la Unión europea prevé también su participación en el procedimiento de revisión simplificada de la Constitución, prevista en el art. IV-444.1 y $2^{126}$.

Este nuevo sistema de legitimación negativa de los parlamentos nacionales puede tener relevancia en el sistema constitucional español, ya que la Comisión mixta para la Unión europea, regulada en la ley 8/1994, de 19 de mayo (anteriormente lo era en la ley 47/85), es bicameral ${ }^{127}$.

3) La participación de las regiones. Mientras los dos instrumentos anteriores, sin duda, mejoran la legitimación democrática de las decisiones comunitarias, las regiones no han visto colmadas sus expectativas de formar parte del entramado de decisión comunitario,

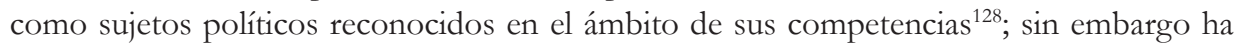
habido tímidos avances frente a la situación jurídica anterior.

La primera novedad es el reconocimiento expreso y el respeto al poder regional, como parte de la estructura de los EEMM, en el art. I-5.1 (Relaciones entre la Unión y los Estados miembros)

«La Unión respetará la igualdad de los Estados miembros ante la Constitución, así como la identidad nacional, inherente a las estructuras fundamentales políticas y constitucionales de éstos, también en lo referente a la autonomía local y regional».

La interpretación inmediata es que la vertebración de estos poderes y su participación en la Unión descansa en cada Estado miembro. Pero, desde la Unión se añade una nueva previsión para la Comisión, que no hace más que formalizar la práctica habitual de esta institución comunitaria, cuando el artículo 2 del protocolo sobre aplicación de los principios de subsidiariedad y proporcionalidad dice:

»Antes de proponer un acto legislativo europeo, la Comisión procederá a amplias

125 «El Tribunal de Justicia de la Unión Europea será competente para pronunciarse sobre los recursos por violación del principio de subsidiariedad, por parte de un acto legislativo europeo, interpuestos con arreglo a los procedimientos establecidos en el articulo III-365 de la Constitución por un Estado miembro, o transmitidos por este de conformidad con su ordenamiento jurídico en nombre de su Parlamento nacional o de una cámara del mismo».

126 «1. Cuando la Parte III disponga que el Consejo se pronuncie por unanimidad en un ámbito o en un caso determinado, el Consejo Europeo podrá adoptar una decisión europea que autorice al Consejo a pronunciarse por mayoría cualificada en dicho ámbito o en dicho caso. El presente apartado no se aplicará a las decisiones que tengan repercusiones militares o en el ámbito de la defensa.

2. Cuando la Parte III disponga que el Consejo adopte leyes o leyes marco europeas por un procedimiento legislativo especial, el Consejo Europeo podrá adoptar una decisión europea que autorice a adoptar dichas leyes o leyes marco por el procedimiento legislativo ordinario.

3. Cualquier iniciativa tomada por el Consejo Europeo en virtud de los apartados 1 o 2 se transmitirá a los Parlamentos nacionales. En caso de oposición de un Parlamento nacional notificada en un plazo de seis meses a partir de esta transmisión, no se adoptará la decisión europea contemplada en los apartados 1 o 2 . A falta de oposición, el Consejo Europeo podrá adoptar la citada decisión.

Para la adopción de las decisiones europeas contempladas en los apartados 1 y 2, el Consejo Europeo se pronunciará por unanimidad, previa aprobación del Parlamento Europeo, que se pronunciará por mayoría de los miembros que lo componen».

127 Pablo PÉREZ TREMPS, «La débil «Parlamentarización» de la integración en España» en Eduardo GARCÍA DE ENTERRÍA (dir.) y Ricado ALONSO GARCÍA (subd.), La encrucijada constitucional de la Unión Europea, Cívitas, Madrid 2002, pp. 401- 415, especialmente p. 405 comentaba que «la existencia de órganos mixtos en parlamentos bicamerales viene a representar una cierta ruptura de la lógica representativa de cada una de las cámaras». 
7. La iniciativa legislativa de la ciudadanía europea y la intervención del Comité de las Regiones y del Comité económico y social, como órganos consultivos en el proceso de decisión son otros de los instrumentos para aumentar la legitimación democrática de las decisiones comunitarias.

Este es brevemente el esquema propuesto. Sin ninguna duda le falta toda una serie de contenidos para hacer posible una auténtica constitucionalización y esos contenidos deberían darlos, fundamentalmente las Constituciones de los Estados miembros.

\section{LOS ESTADOS CONSTITUCIONALES DEL SIGLO XXI}

Me preguntaba al comienzo de este trabajo por la posibilidad de hacer que la «constitucionalización» de la Unión sirviese de modelo para constitucionalizar el gobierno de la economía en el mundo de la globalización. Y creo que es posible, contando con la voluntad de los Estados constitucionales.

Es evidente que el siglo XXI nace con una nueva concepción del Estado constitucional, como Estado abierto a integraciones supranacionales que, en principio no buscan constituir Estados más grandes, sino gestionar en común materias determinadas. Por lo tanto, la fuente de legitimidad democrática no hay que buscarla en un único pueblo (europeo o mundial), sino en cada pueblo, constituido como Estado. Por eso carecemos de momentos constituyentes, propiamente dichos.

Ahora bien, constitucionalizar las nuevas instancias, supone, fundamentalmente, normarlas, es decir, controlar jurídicamente a los órganos que toman las decisiones y asegurar la protección de los derechos de la ciudadanía y para ello, es absolutamente necesario limitar, en la Constitución de cada Estado, sus campos de actuación (competencias) y los principios que deben regir el desarrollo de las mismas, es decir, mientras no se diga otra cosa, los principios del Estado social y democrático de derecho ${ }^{139}$. Es decir, de ese Estado que interviene en la economía para asegurar a todos la procura existencial, ese Estado prestacional, ese Estado redistribuidor de la riqueza ${ }^{140}$.

Para la legitimación democrática de estas decisiones, que serán tomadas, en la mayoría de los casos por órganos que carecen de democracia directa, habrá que crear instrumentos, al menos negativos, como en el caso de la Unión Europea y el control previo de los parlamentos nacionales, que permitan, al menos, una legitimación democrática mediata.

128 De las actuaciones del lobby regional ante la Convención europea he dado cuenta en mi trabajo «El papel de las regiones en la nueva Europa: especial referencia a las Comunidades Autónomas española», Cuadernos Europeos de Deusto, 27/2002, especialmente pp. 55-63. Las regiones comunitarias han quedado lejos del Un modelo federal de tres instancias de gobierno, Unión, Estados y Regiones del que habla Argimiro ROJO SALGADO, El modelo Federalista de Integración Europea: La Europa de los Estados y de las Regiones, Dykinson, Madrid 1996, especialmente pp. 79-81. Un estudio general sobre el poder regional puede verse en Desiderio FERNÁNDEZ MOJÓN, Proyección internacional de la diversidad territorial, IVAP, Bilbao 2003.

129 Esta última frase ha sido introducida por la CIG.

130 «El Consejo de Ministros estará compuesto en cada una de sus formaciones por un representante de rango ministerial nombrado por cada Estado miembro. Este representante será el único facultado para comprometer al Estado miembro al que represente y para ejercer el derecho de voto» decía la versión de la Convención. 
La Comisión General de las Comunidades Autónomas podría ser, haciendo uso de las competencias que tiene en materia europea, la receptora de los dictámenes de los parlamentos autonómicos y, si el parlamento autonómico actúa en el marco de sus competencias, el Senado debería hacer llegar a la Comisión dicho dictamen ${ }^{137}$. Es decir, el Senado, lo único que debería comprobar es que el Parlamento autonómico actúa en el ámbito de sus competencias $^{138}$.

\section{RECAPITULACIÓN}

1. La legitimidad democrática de la Unión europea descansa en la legitimidad democrática que tiene cada Estado miembro, por lo tanto la fuente de legitimidad es cada pueblo europeo dotado de una Constitución; Constitución que es la base del nuevo orden: La Unión Europea.

2. La Constitución de cada Estado miembro es por tanto la norma normarum de la Unión y es ella la que concede, en las materias de su competencia y respetando los principios constitucionales de cada Estado miembro, la primacía al derecho comunitario.

3. El Tribunal de Justicia tiene legitimidad para ser el máximo intérprete del Derecho comunitario, únicamente en el ámbito de las competencias atribuidas a la Unión.

4. Precisamente por eso, deberían detallarse en cada texto constitucional los límites de tal primacía.

5. La atribución del ejercicio de competencias a la Unión es una decisión revocable por parte de los EEMM.

6. La legitimación democrática de las decisiones de la Unión descansa, positivamente, en el Parlamento europeo y, negativamente, en los parlamentos nacionales de los Estados miembros.

131 «De conformidad con los procedimientos establecidos en dicho artículo (artículo III-363), el Comité de las Regiones también podrá interponer recursos contra actos legislativos europeos para cuya adopción la Constitución requiera su consulta».

132 La primera reunión de presidentes de parlamentos de regiones con poderes legislativos se celebró en Oviedo, los días 6 y 7 de octubre de 1997 y a ella acudieron quince presidentes de parlamentos autonómicos españoles (no fueron Navarra ni Canarias) cuatro presidentes alemanes (Baden-Wütemberg, Branderburgo, Baviera y Sajonia), el presidente de la conferencia de presidentes de Austria (presidente de Salzburgo), los presidentes de las cámaras regionales belgas, los presidentes de catorce Consigli regionales italianos y los de las asambleas portuguesas de Azores y Madeira.

133 Más información sobre esta Conferencia en: http://www.calre.be/ES/default.html

134 Toda la información sobre la COSAC puede encontrarse en: http://www.europarl.eu.int/natparl/cosac/ default_en.htm

135 Así lo han venido diciendo en todas sus reuniones: Oviedo 1997, Salzburgo 1998, Florencia 1999, Funchal (Madeira) donde se reunió la quinta CALRE conferencia los días 29 y 30 de octubre de 2001, aprobando su actual reglamento y Bruselas, 27 a 29 de octubre de 2002. Un interesante resumen de los trabajos de la CALRE puede verse en Alberto ARCE JANARIZ, «Las regiones legislativas de la Unión europea», Asamblea. Revista parlamentaria de la Asamblea de Madrid, no 7, diciembre 2002, pp. 3-16.

136 Las expectativas que tenían las regiones pueden verse en el trabajo del Comité de las Regiones de la Unión Europea, Las dimensiones regional y local en el establecimiento de nuevas formas de gobernanza en Europa, MundiPrensa, Luxemburgo 2003. 
137 Enoch ALBERTÍ ROVIRA, «Los parlamentos regionales en la Unión Europea» en Eduardo GARCÍA DE ENTERRÍA (dir.) y Ricado ALONSO GARCÍA (subd.), La encrucijada constitucional de la Unión Europea, Cívitas, Madrid 2002, pp. 351-363, especialmente pp. 358-362 habla de otras formulas de participación posibles.

138 Ésta sería una manera de cumplir lo dicho por R. SMEND Constitución y derecho constitucional, Centro de estudios Constitucionales, Madrid 1985, p. 179, cuando habla de las nacionalidades y regiones dice: «no son meros objetos de integración, sino, sobre todo, protagonistas del proceso integrador. La razón de ser del estado no consiste en amalgamarlas como si se tratase de dos fuerzas hostiles o de ligarlas en lo externo mediante un pacto, sino que consiste en representar la unidad vital de ambas en virtud de una necesidad intrínseca». 
Si las Constituciones no hacen esto, corremos el peligro de acabar, por amor a integraciones necesarias, con las bases de un Estado, el social y democrático de derecho, cuyo objetivo era el bienestar general y repetir una etapa, la liberal, de funestas consecuencias ${ }^{141}$.

La inclusión de cláusulas europeas en los textos constitucionales de cada Estado miembro es, en definitiva, un instrumento adecuado para constitucionalizar la Unión ${ }^{142}$.

139 La dificultad que existe hoy en día para eso es estudiada por Antonio LÓPEZ PINA e Ignacio GUTIÉRREZ, Elementos de Derecho Público, Marcial Pons, Madrid 2002, especialmente pp. 60-67.

140 Porque como muy bien dice Javier GARCÍA ROCA, «Estatalidad versus Soberanía» en Alberto PÉREZ CALVO (coord.), Estado, Nación y soberania, Temas del Senado, Madrid 2000, pp. 291-311, especialmente en las pp. 310-311 «Pero no puede abandonarse esa estatalidad, (...) al menos mientras la Unión Europea no satisfaga los mismos fines políticos y sociales que el Estado cumple»; Más adelante señala que es preciso construir un conjunto de reglas que permitan mantener la legitimidad democrática y la naturaleza social del Estado.

141 Utilizando palabras de Javier RUIPÉREZ, «¿La Constitución en crisis? El estado constitucional democrático y social en los tiempos del neoliberalismo tecnocráticom, Revista de Estudios Politicos, $\mathrm{n}^{\circ}$ 120, abrilmayo 2003, pp. 127-171, especialmente p. 146: «el proyecto de unidad mundial desde la globalización económica me parece tributario de una concepción del mundo que, a la postre se convirtió en una de las principales causas que condujeron al viejo Estado liberal a una situación de crisis total y que, por último, determinaron su substitución por el estado social....».

142 En el mismo sentido se pronunciaba hace ya algún tiempo, Peter HÄBERLE, «Programas sobre Europa en constituciones y proyectos constitucionales recientes. El desarrollo del «Derecho constitucional nacio- 
nal sobre Europa», en Peter HÄBERLE, Retos actuales del Estado constitucional, IVAP, Bilbao 1995, p. 130: «La defensa a favor de más artículos europeos generales y especiales en las Constituciones internas en el sentido de «Europa en el Estado constitucional» no quiere constreñir la futura política europea, sino legitimarla desde la proximidad al ciudadano, regional y nacionalmente, más desde abajo». 